\title{
Impact of Tobacco Control Interventions on Smoking Initiation, Cessation, and Prevalence: A Systematic Review
}

\author{
Lisa M. Wilson, ${ }^{1}$ Erika Avila Tang, ${ }^{2,3}$ Geetanjali Chander, ${ }^{1}$ Heidi E. Hutton, ${ }^{4}$ \\ Olaide A. Odelola, ${ }^{5}$ Jessica L. Elf, ${ }^{2,3}$ Brandy M. Heckman-Stoddard, ${ }^{6}$ Eric B. Bass, ${ }^{1,7}$ \\ Emily A. Little, ${ }^{1}$ Elisabeth B. Haberl, ${ }^{1}$ and Benjamin J. Apelberg ${ }^{2,3}$ \\ ${ }^{1}$ Division of General Internal Medicine, Johns Hopkins University School of Medicine, Baltimore, MD 21205, USA \\ ${ }^{2}$ Department of Epidemiology, Institute for Global Tobacco Control, Johns Hopkins University Bloomberg School of Public Health, \\ Baltimore, MD 21205, USA \\ ${ }^{3}$ Department of Health, Behavior and Society, Institute for Global Tobacco Control, Johns Hopkins University Bloomberg School of \\ Public Health, Baltimore, MD 21205, USA \\ ${ }^{4}$ Department of Psychiatry and Behavioral Sciences, Johns Hopkins University School of Medicine, Baltimore, MD 21287, USA \\ ${ }^{5}$ Department of Internal Medicine, Albert Einstein Medical Center, Philadelphia, PA 19141, USA \\ ${ }^{6}$ Cancer Prevention Fellowship Program, Division of Cancer Prevention, National Cancer Institute, Bethesda, MD 20892, USA \\ ${ }^{7}$ Department of Health Policy and Management, Johns Hopkins University Bloomberg School of Public Health, Baltimore, MD, USA
}

Correspondence should be addressed to Lisa M. Wilson, lisawilson@jhmi.edu

Received 2 December 2011; Accepted 8 March 2012

Academic Editor: Vaughan Rees

Copyright (c) 2012 Lisa M. Wilson et al. This is an open access article distributed under the Creative Commons Attribution License, which permits unrestricted use, distribution, and reproduction in any medium, provided the original work is properly cited.

Background. Policymakers need estimates of the impact of tobacco control (TC) policies to set priorities and targets for reducing tobacco use. We systematically reviewed the independent effects of TC policies on smoking behavior. Methods. We searched MEDLINE (through January 2012) and EMBASE and other databases through February 2009, looking for studies published after 1989 in any language that assessed the effects of each TC intervention on smoking prevalence, initiation, cessation, or price participation elasticity. Paired reviewers extracted data from studies that isolated the impact of a single TC intervention. Findings. We included 84 studies. The strength of evidence quantifying the independent effect on smoking prevalence was high for increasing tobacco prices and moderate for smoking bans in public places and antitobacco mass media campaigns. Limited direct evidence was available to quantify the effects of health warning labels and bans on advertising and sponsorship. Studies were too heterogeneous to pool effect estimates. Interpretations. We found evidence of an independent effect for several TC policies on smoking prevalence. However, we could not derive precise estimates of the effects across different settings because of variability in the characteristics of the intervention, level of policy enforcement, and underlying tobacco control environment.

\section{Introduction}

Tobacco smoking is one of the leading causes of preventable death, responsible for over 5 million deaths annually [1]. Currently, more than 1 billion people smoke, with over $80 \%$ living in low- and middle-income countries [2]. However, countries are at different stages of the tobacco epidemic [3]. Many countries have achieved substantial declines in smoking and tobacco-related disease through the implementation of comprehensive tobacco control programs, while others are experiencing increases in smoking prevalence.
Tobacco control efforts have evolved over time as evidence has grown to support the use of different approaches. The population-based approaches most commonly used have included increased taxes, public education through mass media campaigns and health warnings, tobacco marketing restrictions, and the introduction of smoke-free indoor environments.

With the introduction of the World Health Organization's (WHO) Framework Convention on Tobacco Control (FCTC) [4] and MPOWER (Monitor, Protect, Offer, Warn, Enforce, Raise) policy package [5], tobacco control policies 
are being implemented worldwide. To model the impacts of these policies and develop achievable targets for smoking prevalence, policy makers need estimates of the independent effects of interventions on smoking behavior. We performed a systematic review to evaluate the independent effect on smoking prevalence of four tobacco control policies outlined in the WHO MPOWER Package [5]: increasing taxes on tobacco products, banning smoking in public places, banning advertising and sponsorship of tobacco products, and educating people through health warning labels and antitobacco mass media campaigns (Table 1). We focused on the degree of certainty in the estimated impact and factors that may influence the impact.

\section{Methods}

2.1. Study Design and Scope. For our systematic review of published studies, smoking was defined as the use of cigarettes and/or other smoked products, such as cigars, cigarillos, bidis, hookahs, water pipes, and kreteks. We excluded smokeless tobacco products. Outcomes of interest were smoking prevalence, initiation or cessation rates, and price participation elasticity (PPE) (the relative percentage change in smoking prevalence for every $1 \%$ change in price). We excluded outcomes such as quit attempts or tobacco consumption because they did not directly address the impact of interventions on smoking prevalence.

2.2. Search Strategy. We searched five databases: MEDLINE (accessed via PubMed, January 1950 through January 2012), EMBASE (January 1974 through February 2009), The Cochrane Library (Issue 1, 2009), the Cumulative Index to Nursing and Allied Health Literature (CINAHL, January 1982 through February 2009), and PsycInfo (from inception through February 2009). Our electronic search strategy used medical subject headings and text words for smoking and the tobacco control interventions and was limited to human subjects (see the appendix for the MEDLINE search string). We reviewed recent issues of ten economics and public health journals, reference lists of included articles, relevant reviews, books, and reports.

2.3. Study Selection. Two reviewers independently assessed titles, abstracts, and articles for inclusion. We included peerreviewed studies published in any language that: measured smoking prevalence, initiation, cessation, or PPE; assessed the independent effects of at least one of the tobacco control interventions; met our study design criteria (Table $1)$. Because modeling approaches typically require estimates of independent effects, we excluded studies evaluating multicomponent interventions. Studies published prior to 1990 were excluded because the smoking population may have changed over time. Conflicts on eligibility were resolved through consensus.

2.4. Data Extraction. Reviewers used a Web-based system to extract data from eligible studies on study design, interventions, and smoking prevalence. Extracted data were checked by a second reviewer. Study quality was assessed independently by two reviewers.

We were unable to conduct meta-analyses because of the heterogeneity of the studies. Instead, we prepared a qualitative summary of results by intervention type and highlighted key sources of heterogeneity.

2.5. Grading of Evidence. We graded the quantity, quality, and consistency of results based on the GRADE working group criteria [6]. "High" strength of evidence indicates high confidence that the evidence reflects the true effect, and further research is very unlikely to change the result. "Moderate" strength of evidence indicates moderate confidence that the evidence reflects the true effect, and further research may change the result. "Low" strength of evidence indicates low confidence that the evidence reflects the true effect, and further research is likely to change the result. An "insufficient" grade indicates that no evidence was available to quantify the independent effect.

2.6. Role of the Funding Source. The International Union Against Tuberculosis and Lung Disease suggested the topic, but was not involved in the collection, analysis, and interpretation of the data, or in the writing of the paper. The authors retained full control over the conduct and reporting of the paper.

\section{Results}

3.1. Search Results. From our search of 20,102 unique citations, we included 84 studies (88 publications) (Figure 1). Thirty-five evaluated taxation, 29 evaluated smoking bans, 5 evaluated advertising or sponsorship bans, 4 evaluated health warning labels, and 19 evaluated mass media campaigns. Twelve studies assessed smoking initiation (11 among youths), 25 assessed smoking cessation (4 among youths), and 52 (19 among youths) assessed smoking prevalence. Eight studies were conducted in low- and middle-income countries. The overall summary of the evidence for these interventions is presented in Table 2.

3.2. Increasing Taxes on Tobacco Products. We found high strength of evidence to quantify the impact of increases in tobacco pricing. The PPEs ranged from -1.41 to -0.10 (interpreted as a $1-14 \%$ decrease in smoking prevalence for every $10 \%$ increase in price) among youths and -0.45 to 0.10 among adults. The larger PPE for youths is consistent with prior evidence that young people are more price sensitive due to lower levels of disposable income.

3.2.1. Youths. Five [7-11], one [12], and nine studies [1321] evaluated the impact of increased taxes on smoking initiation, cessation, and prevalence among youths, respectively (Table 3 ). All but four $[8,15,16,19]$ were conducted in the US. One study was conducted among youths in 17 low- and middle-income countries [15]. Of the five studies examining smoking initiation, four found a statistically significant negative association with increasing taxes/prices 
TABLE 1: Definitions of the tobacco control interventions.

\begin{tabular}{|c|c|c|}
\hline Key question & Intervention definition & Study design criteria \\
\hline Taxation & Any change in price or tax on cigarettes & (i) cluster randomized trial \\
\hline $\begin{array}{l}\text { Banning } \\
\text { smoking in } \\
\text { public places }\end{array}$ & $\begin{array}{l}\text { Policy or legislative change at the national, state, or community level that prohibits } \\
\text { or restricts smoking in indoor environments. The target of the ban or restriction } \\
\text { could include worksites, public places, and bars and/or restaurants. Smoking bans } \\
\text { are classified as (1) complete when } 100 \% \text { smoke-free or no smoking allowed in any } \\
\text { indoor area; (2) partial when smoking is restricted or limited to designated areas. } \\
\text { We excluded smoking bans that were conducted among a specialized population, } \\
\text { such as hospitalized patients, military recruits, or prisoners. While we did not } \\
\text { include specific worksite smoking bans, we included studies conducted among } \\
\text { specific workers if it evaluated a policy or legislative smoking ban }\end{array}$ & $\begin{array}{l}\text { (iii) pre-/post- repeated } \\
\text { cross-sectional study with a } \\
\text { comparison group } \\
\text { (iv) pre-/post- repeated } \\
\text { cross-sectional study without a } \\
\text { comparison group* } \\
\text { (v) time series analysis }\end{array}$ \\
\hline $\begin{array}{l}\text { Banning } \\
\text { advertising and } \\
\text { sponsorship }\end{array}$ & $\begin{array}{l}\text { Ban or restriction on advertising or sponsorship, which may include television, } \\
\text { radio, print, or internet advertising, point of purchase displays, product placement, } \\
\text { and sponsorship of any type of event }\end{array}$ & \\
\hline $\begin{array}{l}\text { Health warning } \\
\text { labels }\end{array}$ & $\begin{array}{l}\text { Any required changes to the packaging of tobacco products intended to disseminate } \\
\text { health warnings or eliminate the use of terms implying a safer product (e.g., } \\
\text { changes to graphic images or text of health warning labels or restrictions on the use } \\
\text { of terms, such as "mild," "low tar," or "light") }\end{array}$ & \\
\hline $\begin{array}{l}\text { Mass media } \\
\text { campaigns }\end{array}$ & $\begin{array}{l}\text { Any campaign intended to reduce tobacco use using "channels of communication } \\
\text { such as television, radio, newspapers, billboards, posters, leaflets, or booklets } \\
\text { intended to reach large numbers of people, which are not dependent on } \\
\text { person-to-person contact" [108] }\end{array}$ & \\
\hline
\end{tabular}

(PPE for initiation ranged from -0.65 to -0.09 ) [7-10], while the other did not (PPE for initiation, -0.003) [11]. All nine studies evaluating youth smoking prevalence found a significant negative effect of taxes/prices, at least among a subset of their samples [13-21]. The study conducted among low- and middle-income countries reported a PPE for local brands of -0.74 and a PPE for foreign brands of -1.09 [15]. The study examining smoking cessation found a price elasticity of cessation of 1.15 among males and 1.17 among females [12].

3.2.2. Adults. Six studies evaluated the impact of taxes/prices on smoking cessation among adults $[12,22-26]$. Three found a statistically significant effect of taxes/price [12, 24, 25], while one found an impact only in the short term (4 months) [26]. One study found a significant association when evaluating prices, but not province-level taxes [22]. One study conducted in Mexico reported a $13 \%$ quit rate after a tax increase [23]. Twelve [25, 27-37] of 16 studies evaluating the effects of taxes/prices on adult smoking prevalence demonstrated a significant negative impact among at least a subset of their sample. Statistically significant effects of price/tax on smoking prevalence were consistently found in studies in high-income countries, such as the US [25, 31-33, 37], Australia [27, 30, 35], and Italy [34]. However, one study conducted in the European Union failed to find a correlation between cigarette affordability and smoking prevalence [38]. The results from low- and middle-income countries were more heterogeneous. Studies in South Africa and Russia found a significant decrease in smoking prevalence after a tax/price increase, with an estimated PPE of -0.30 and -0.10 , respectively $[29,36]$. A study in Mexico found a price elasticity of demand (i.e., the relative percentage change in demand for a $1 \%$ change in price) of -0.52 , but the PPE was only -0.06 [39]. However, data on smoking participation was based on the purchasing patterns of all members of the household, meaning that an impact is only observed if all members of the household quit. A recent study in China [29] also found a relatively small PPE, which may be explained by the high level of affordability and the wide range of cigarette prices, which allows smokers to substitute a lower cost brand [40].

3.3. Banning Smoking in Public Places. We found moderate strength of evidence to quantify the impact of smoking bans. Twenty-nine studies measured the independent effect of smoking bans on initiation ( 2 studies), cessation ( 9 studies), and/or prevalence of smoking (20 studies). The strongest evidence was observed among studies of smoking prevalence, compared with studies assessing smoking initiation and cessation.

The studies that evaluated smoking initiation reported mixed results (Table 4) [41, 42].

Of the nine studies that evaluated smoking cessation, three had a concurrent comparison group [41, 43, 44]. Two studies found no significant association between the smoking ban and cessation rates (adjusted odds ratios ranging from 0.91 to 0.95 ) $[43,44]$, while the other found a significantly lower cessation rate (adjusted odds ratios ranging from 0.65 to 0.66 ) [41]. The other studies lacked a comparison group, making it difficult to draw conclusions. Four studies reported quit rates ranging from 5\% to $15 \%$ [45-48], another reported a $5.1 \%$ increase in the quit rate in the 3 -month period prior to the ban [49], and the other reported a $7.0 \%$ absolute 


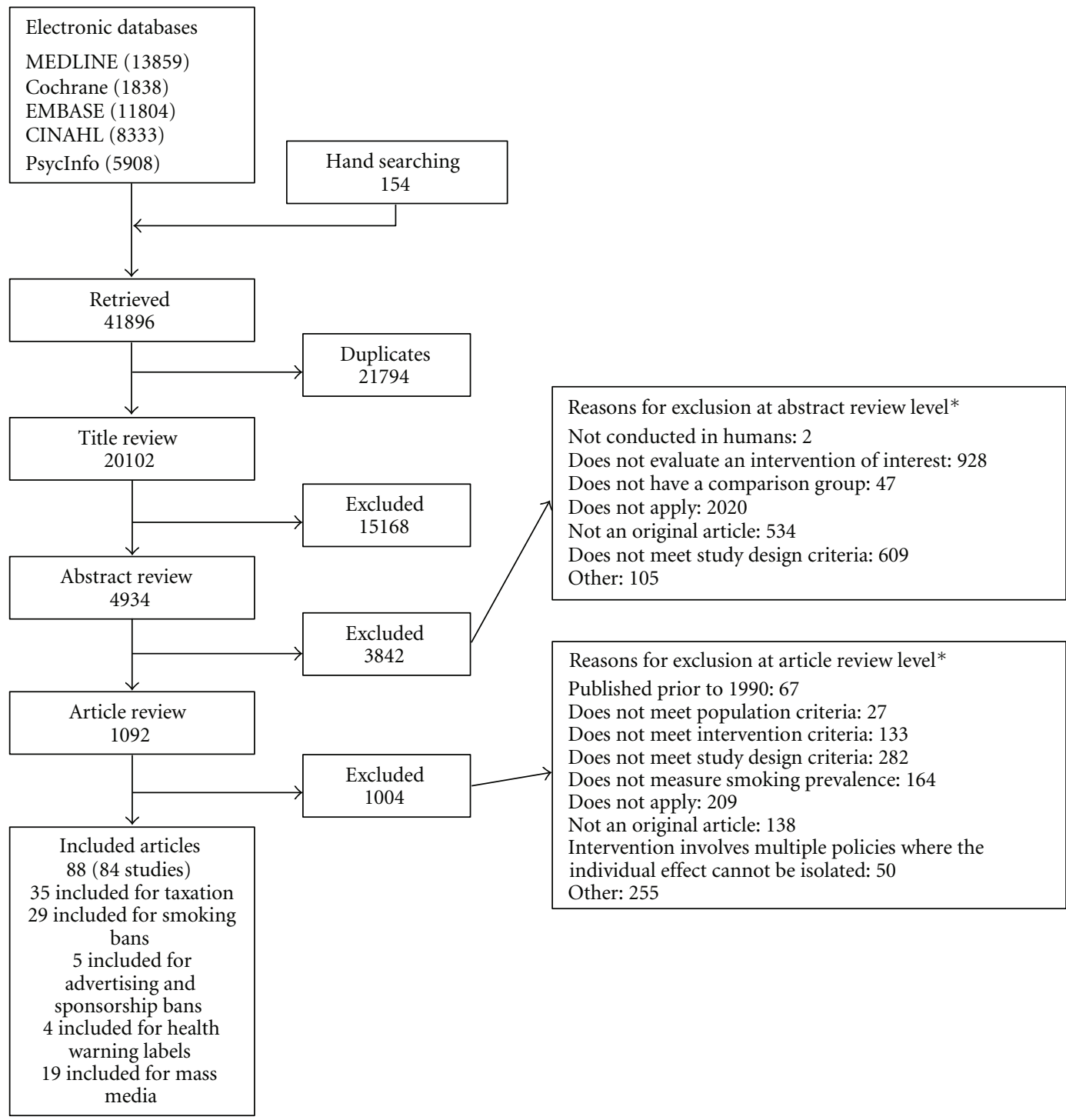

* Total may exceed number in corresponding box, as articles could be excluded for more than one reason at this level.

FIGURE 1: Summary of the literature search (number of articles).

difference in quit rates between those employed and those unemployed [50].

The effectiveness of a smoking ban likely depends on the comprehensiveness of legislation, level of enforcement, public support, and degree of prior legislation in place. Three studies evaluating a new, local, and comprehensive smoking ban reported the strongest effects on smoking prevalence [51-53]. In Saskatoon, Canada, smoking prevalence dropped from $24.1 \%$ to $18.2 \%$ one year after the ban [53]. In Lexington-Fayette County, Kentucky, smoking prevalence declined from $25.7 \%$ to $17.5 \% 20$ months after the ban [52]. Another study conducted among college students in two different counties in Kentucky (Lexington-Fayette county and Louisville Metro) reported significant decreases in smoking prevalence 3.5 years $(P=0.005)$ and 8 months after their respective smoking bans [51]. However, a cohort study in Minnesota found no significant impact on smoking prevalence [54].

Studies conducted at the national level, where tobacco control activities have been ongoing tended to find less dramatic changes in smoking prevalence. For example, an Italian pre-/post- study without a comparison group found a significant decline in smoking prevalence among men $(-8.5 \%, P<0.05)$ and younger Italians $(-7.4 \%, P<$ 0.05) following the introduction of a complete smoking ban [55]. In Spain, a study found a lower than expected smoking prevalence 1 year after the implementation of a partial smoking ban, but smoking prevalence returned to normal 3 years after the ban [56]. Similarly, a time series analysis in Scotland found a significant reduction in smoking prevalence 3-6 months before the law (which may have been influenced by the media coverage preceding the ban), 
TABLE 2: Overall summary of the impact of tobacco control interventions on smoking initiation, cessation, and prevalence.

\begin{tabular}{|c|c|}
\hline Intervention & Smoking behavior \\
\hline $\begin{array}{l}\text { Increasing the price } \\
\text { through taxation }\end{array}$ & $\begin{array}{l}\text { Overall: high* evidence to estimate the independent impact on smoking behavior } \\
\text { Initiation: moderate evidence, } 4 \text { out of } 5 \text { longitudinal studies demonstrated some effectiveness; PPE of initiation } \\
\text { ranged from }-0.65 \text { to }-0.09 \\
\text { Cessation: moderate evidence, price elasticity of cessation ranged from } 0.375 \text { to } 1.17 \\
\text { Prevalence: high evidence, suggesting effectiveness } \\
\text { PPEs ranged from }-1.41 \text { to }-0.10 \text { among youths and }-0.45 \text { to } 0.10 \text { among adults }\end{array}$ \\
\hline $\begin{array}{l}\text { Banning smoking in } \\
\text { public places }\end{array}$ & $\begin{array}{l}\text { Overall: moderate evidence to estimate the independent impact on smoking behavior } \\
\text { Initiation: low evidence, unable to make a conclusion due to equivocal results } \\
\text { Cessation: low evidence, } 2 \text { of } 3 \text { longitudinal studies with comparison groups did not find a significant change in } \\
\text { cessation rates after implementation } \\
\text { Prevalence: moderate evidence, suggesting effectiveness; } \\
\text { Percentage change in prevalence }{ }^{\dagger} \text { ranged from }-31.9 \% \text { to }-7.4 \% \text { compared with control groups after } 1 \text { to } 3.5 \\
\text { years }\end{array}$ \\
\hline $\begin{array}{l}\text { Banning advertising } \\
\text { and sponsorship of } \\
\text { tobacco products }\end{array}$ & $\begin{array}{l}\text { Overall: insufficient evidence to estimate the independent impact on smoking behavior } \\
\text { Initiation: insufficient evidence, unable to make a conclusion because no studies were included } \\
\text { Cessation: insufficient evidence, unable to make a conclusion because no studies were included } \\
\text { Prevalence: low evidence, unable to make a conclusion due to low quality studies; } \\
\text { Two studies among adults showing no effectiveness, } 2 \text { studies among youths showing some effectiveness }{ }^{\ddagger} \text {, and } 1 \\
\text { found an increased prevalence with stronger laws }\end{array}$ \\
\hline $\begin{array}{l}\text { Educating people } \\
\text { about the dangers of } \\
\text { smoking through } \\
\text { health warning labels }\end{array}$ & $\begin{array}{l}\text { Overall: insufficient evidence to estimate the independent impact on smoking behavior } \\
\text { Initiation: insufficient evidence, unable to make a conclusion because no studies were included } \\
\text { Cessation: low evidence, } 2 \text { studies showing no effectiveness } \\
\text { Prevalence: low evidence, } 2 \text { studies showing no effectiveness }\end{array}$ \\
\hline $\begin{array}{l}\text { Educating people } \\
\text { about the dangers of } \\
\text { smoking through } \\
\text { mass media } \\
\text { campaigns }\end{array}$ & $\begin{array}{l}\text { Overall: moderate evidence to estimate the independent impact on smoking behavior } \\
\text { Initiation: moderate evidence, suggesting effectiveness } \\
\text { One cluster RCT demonstrated no effectiveness, but } 4 \text { longitudinal studies suggested a reduced initiation rate } \\
\text { (odds of initiating smoking ranged from } 0.67 \text { to } 0.8)^{\uparrow} \\
\text { Cessation: low evidence, unable to make a conclusion due to equivocal results. } \\
\text { Seven studies with comparison groups showed equivocal results^} \\
\text { Prevalence: moderate evidence, suggesting effectiveness. } \\
\text { Odds of being a smoker } 1 \text { to } 6 \text { years after start of intervention* ranged from } 0.62 \text { to } 0.93^{\S} \text {, but one cluster RCT } \\
\text { showed no effect on smoking prevalence }\end{array}$ \\
\hline
\end{tabular}

\footnotetext{
${ }^{*}$ Grading classification: high strength of evidence indicates high confidence that the evidence reflects the true effect, and further research is very unlikely to change the result. Moderate strength of evidence indicates moderate confidence that the evidence reflects the true effect, and further research may change the result. Low strength of evidence indicates low confidence that the evidence reflects the true effect, and further research is likely to change the result. Insufficient indicates that no evidence was available.

${ }^{\dagger}$ One of these studies stratified results by gender and age (\% impact on prevalence rate after 2 years for those under age 45 years $=-7.4 \%$ and for those aged 45 years and older $=-1.4 \%$ ).

₹These studies had severe methodological flaws that limit our ability to make conclusions.

"The strongest study methodologically showed a hazard ratio of 0.8 (95\% CI: $0.71,0.91 ; P=0.001)$ per 10,000 GRP cumulative exposure.

${ }^{\wedge}$ Two of the pre-/post- cross-sectional studies were methodologically stronger than the others. One study reported an odds ratio of cessation $=1.27$ ( $95 \%$ CI: 0.77 to 2.08 ). The other reported a relative risk of quitting $=1.1$ ( $95 \%$ CI: 0.98 to 1.24$)$ per 5,000 GRPS.

$\S$ Additionally, a well-conducted time series analysis reported a decrease in percentage point prevalence two months later of -0.00077 per 1 GRP per month increase $(P=0.025)$. This is the equivalent of each person viewing an average of 4 ads per month to achieve a 0.30 percentage point decline in smoking prevalence.

CI: confidence intervals; GRP: gross rating point; PPE: price participation elasticity; RCT: randomized controlled trial.
}

but no significant change 9 months after the law [57]. In Ireland, two studies (reported in the same publication [58]) found a nonsignificantly lower smoking prevalence 1 year after implementation of a complete smoking ban among bartenders and the general public. Other studies conducted in Spain [59], Scotland [41, 60], England [61, 62], Germany [63], and The Netherlands (a partial smoking ban exempting the hospitality industry) [64] found no significant impact of a smoking ban on smoking prevalence. Wakefield et al. found no significant impact of an incremental increase in the population covered by smoke-free restaurant-specific laws on monthly smoking prevalence in Australia [27]. However, another study conducted in Australia among youths 12-17 years old found a lower smoking prevalence with stronger smoking bans (adjusted odds ratio, 0.93; 95\% confidence interval (CI), 0.92-0.94) [16]. Two US studies evaluated the effects of venue-specific smoking bans among workers most affected by those laws $[65,66]$. Both studies found a decreased smoking prevalence among bartenders after smoking bans in bars, but no change in other workers [66]. Another study conducted in the US-categorized state smoking bans by the number and type of restrictions and reported their results stratified by age group [33]. State smoking bans were largely insignificant, but this is probably 


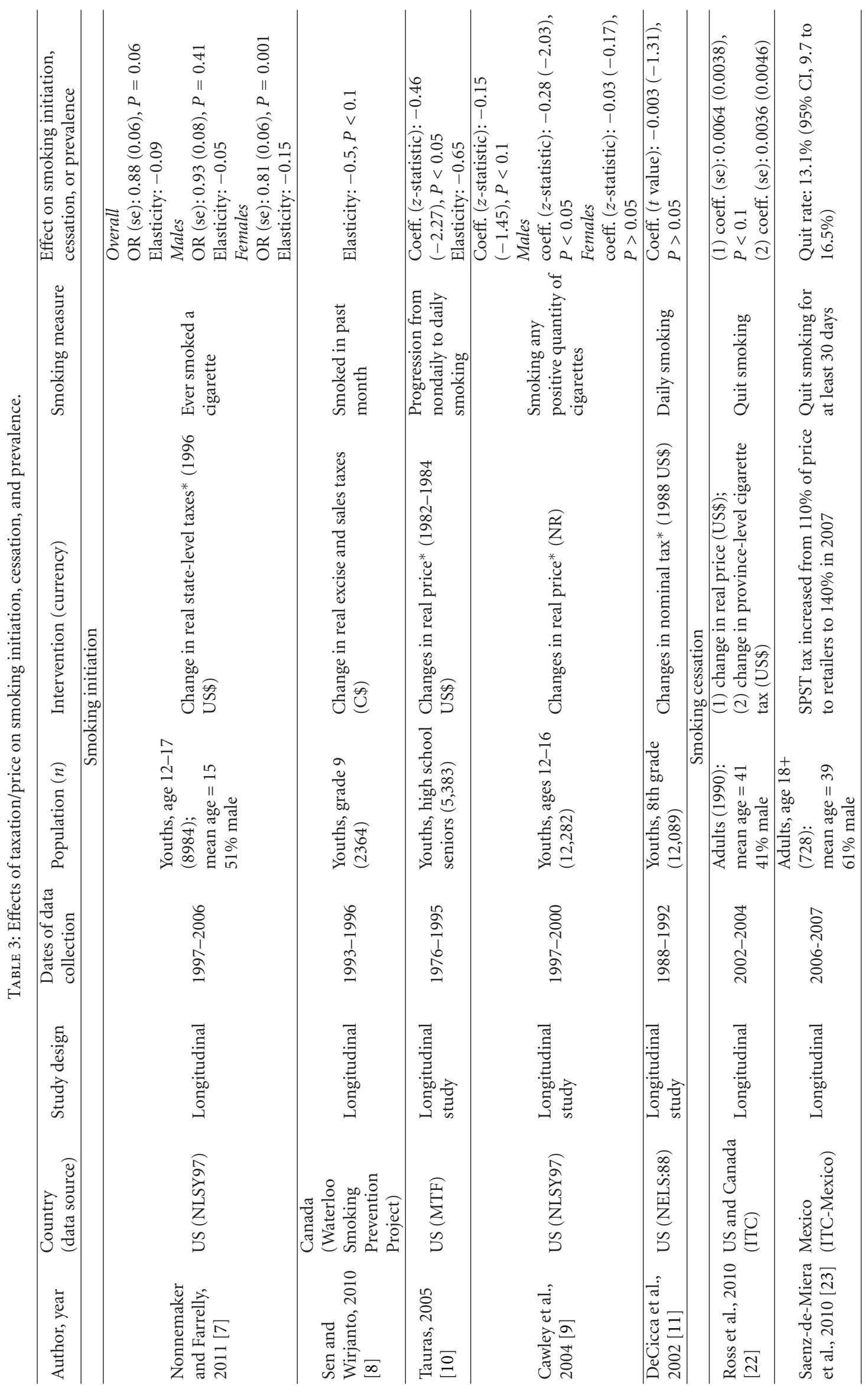




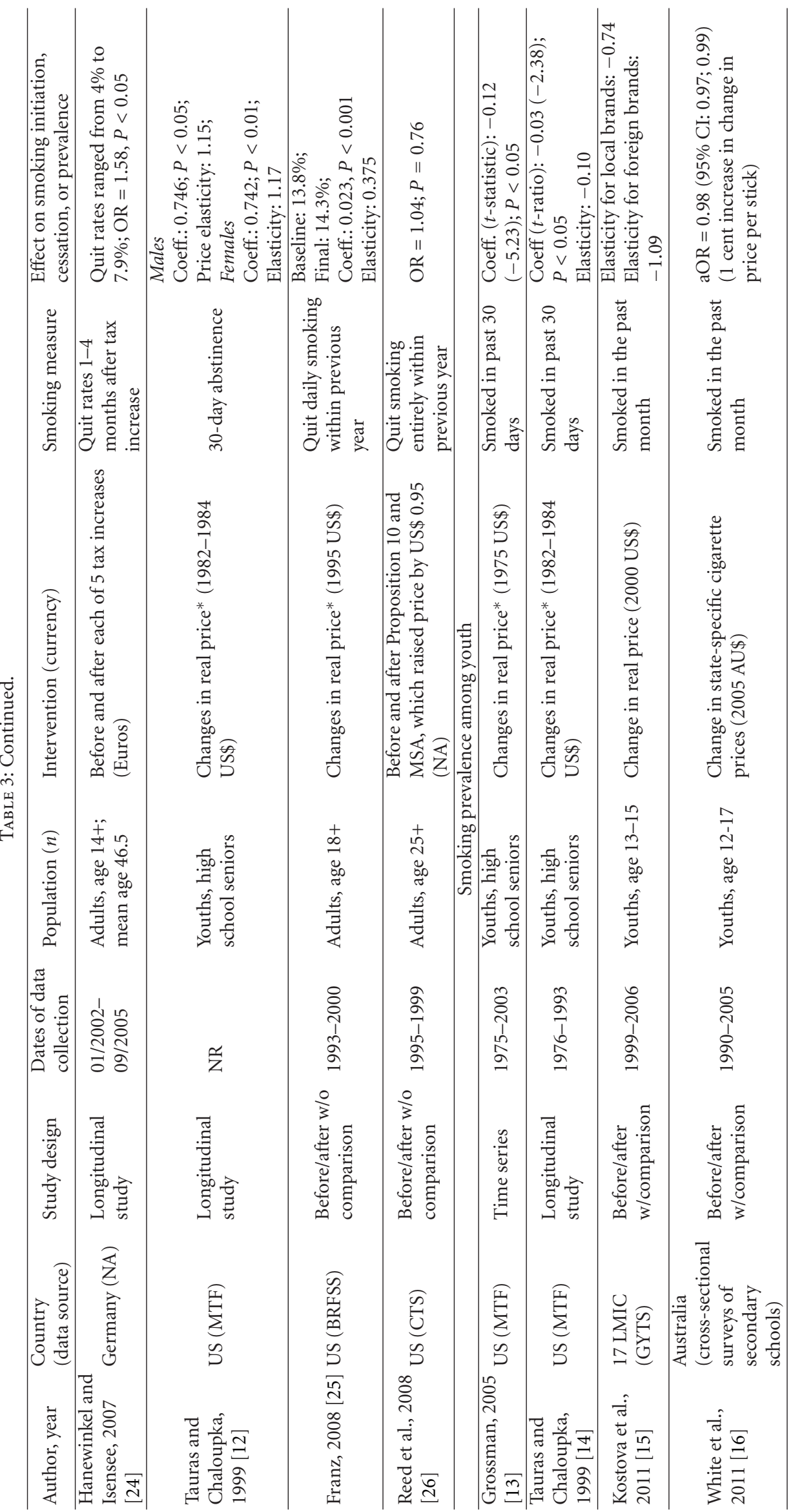




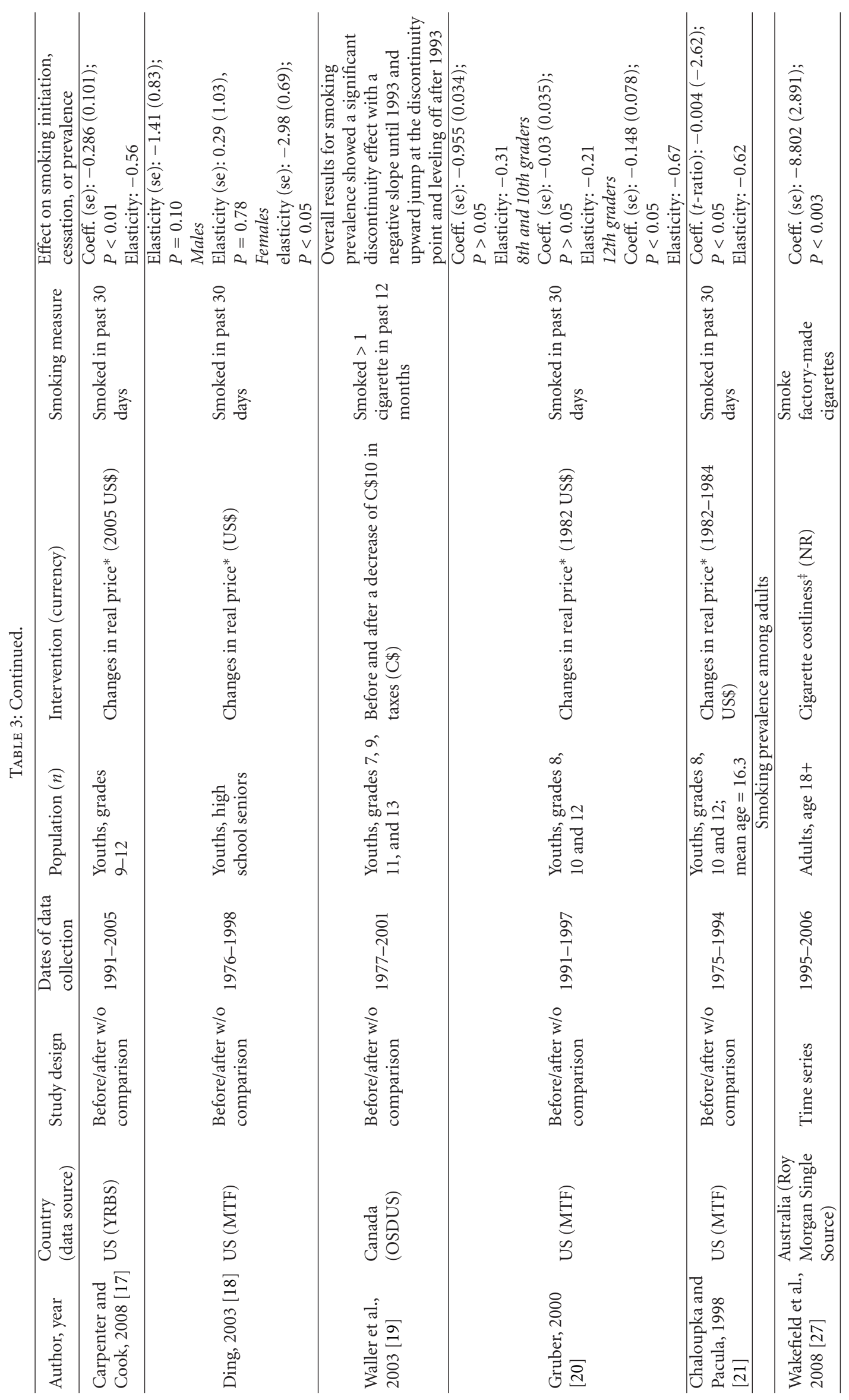




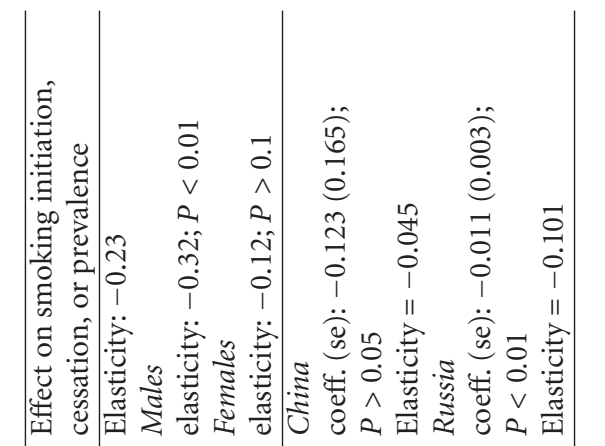

\section{(2)}



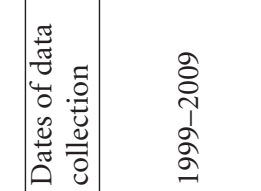

صृ

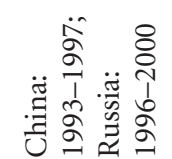

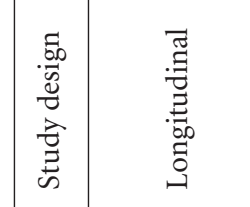

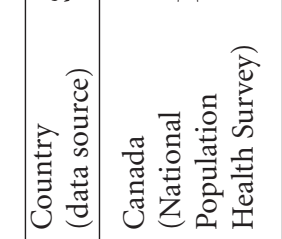

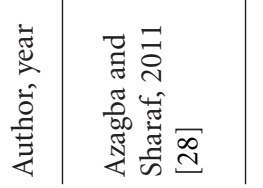

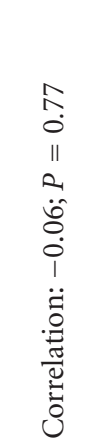

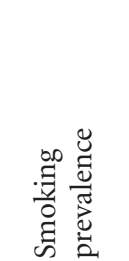

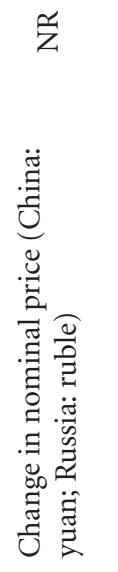

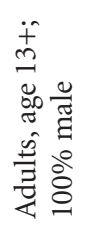

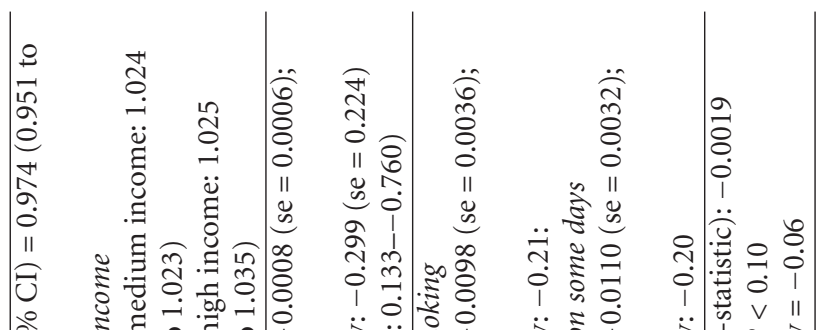

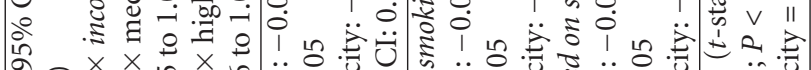

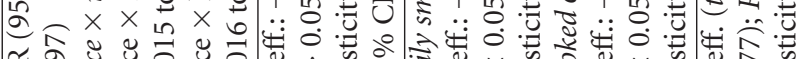

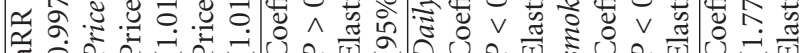

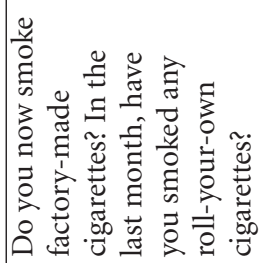

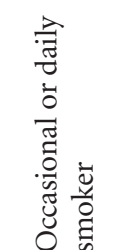

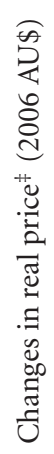

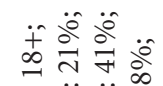

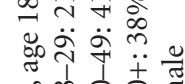

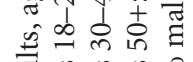

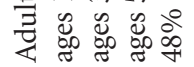

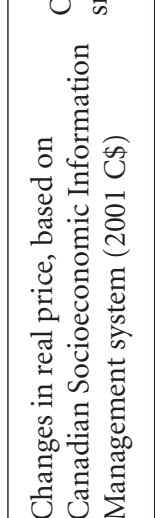

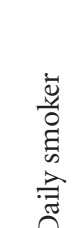

$\vec{\nabla}$

풍 5

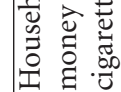

范

운 훙

竞

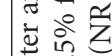

की मृ

के पे

유월

市等

䒕

劳命 20

苛

竞苛

吾壱

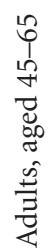

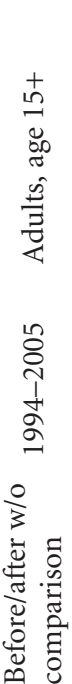

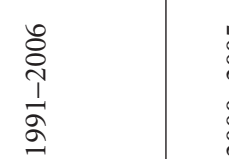

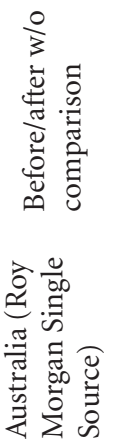

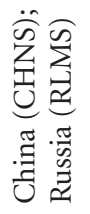

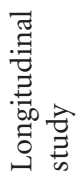

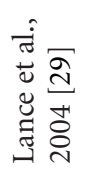

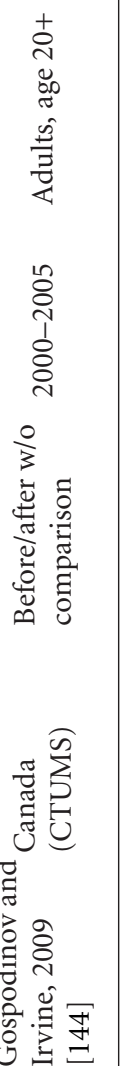

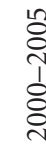

$\frac{1}{3}$

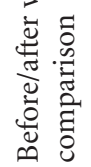

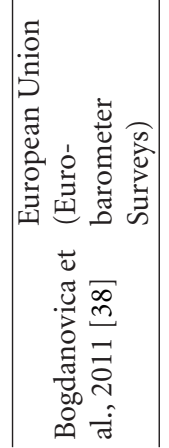

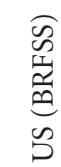

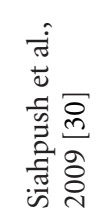

च

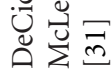

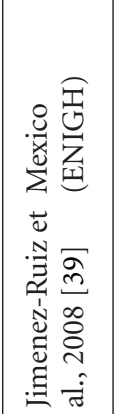




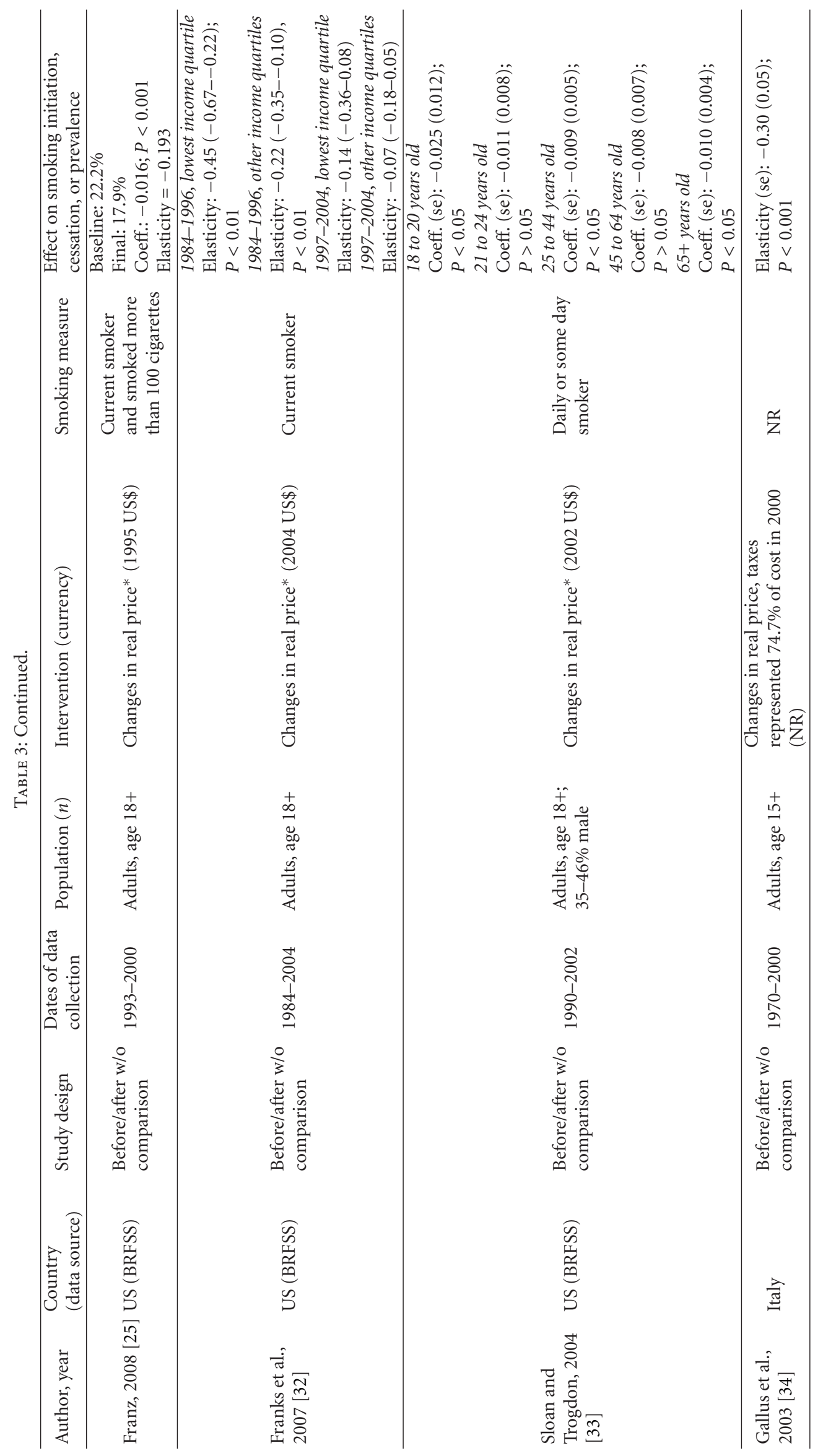




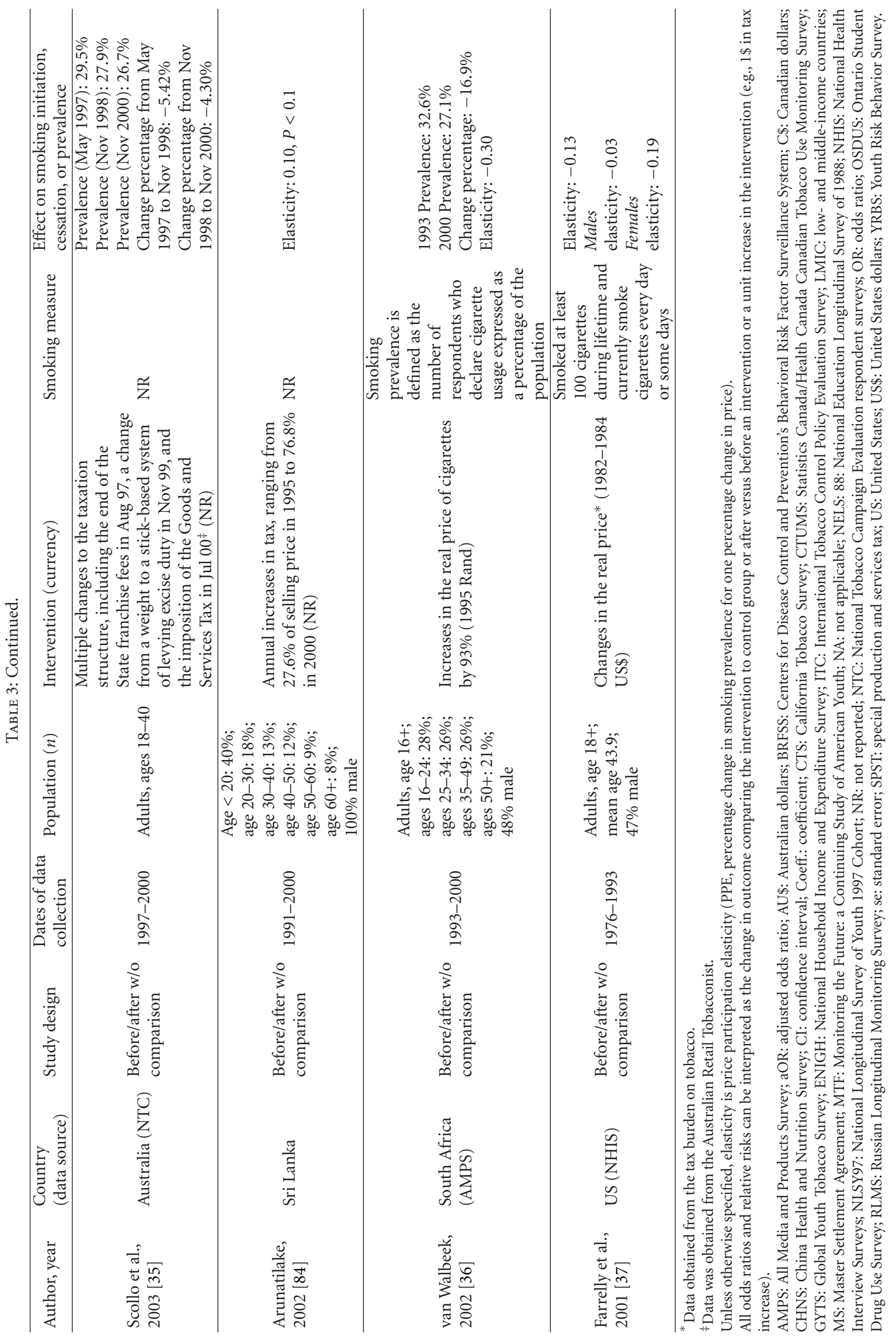




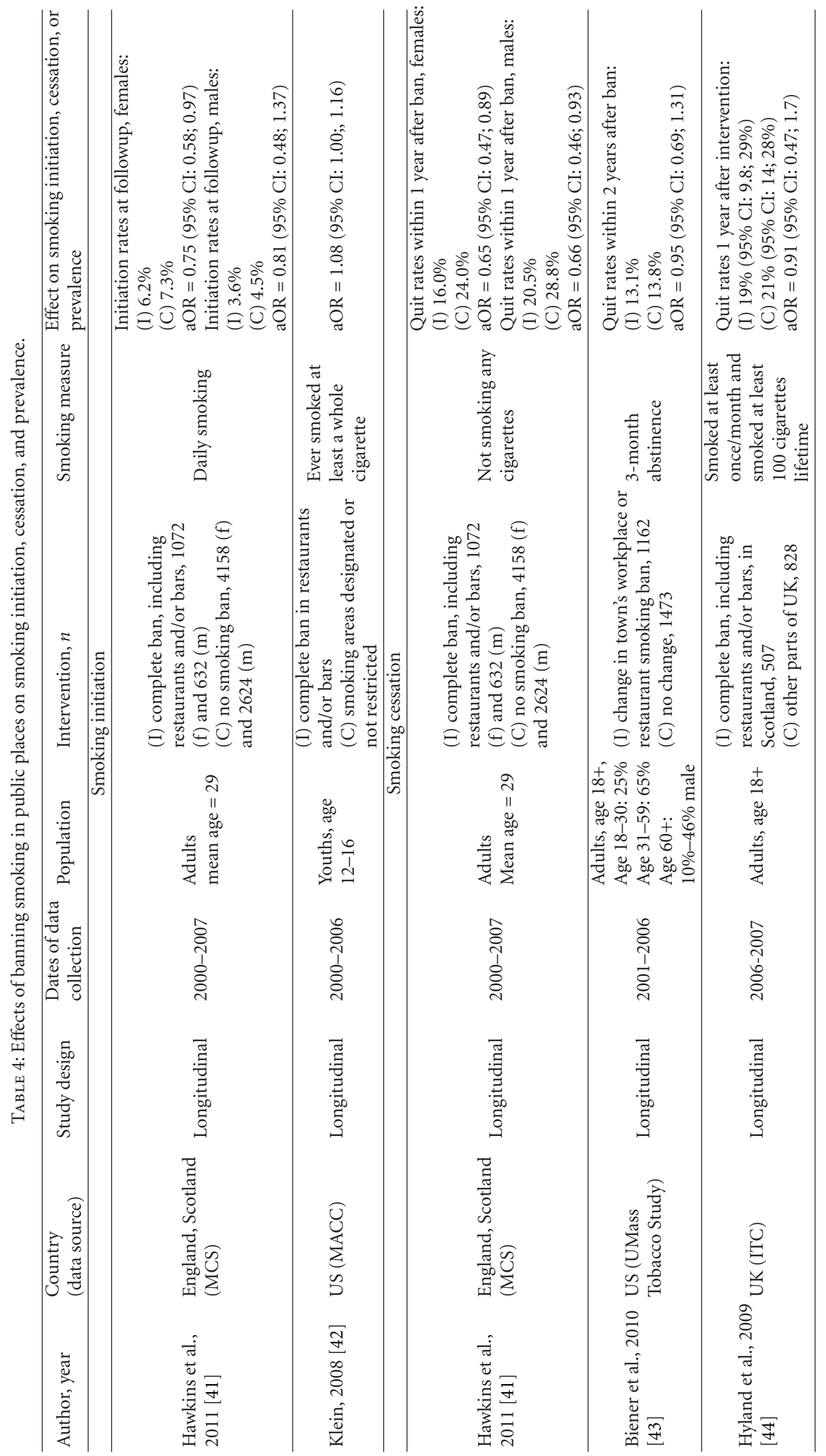




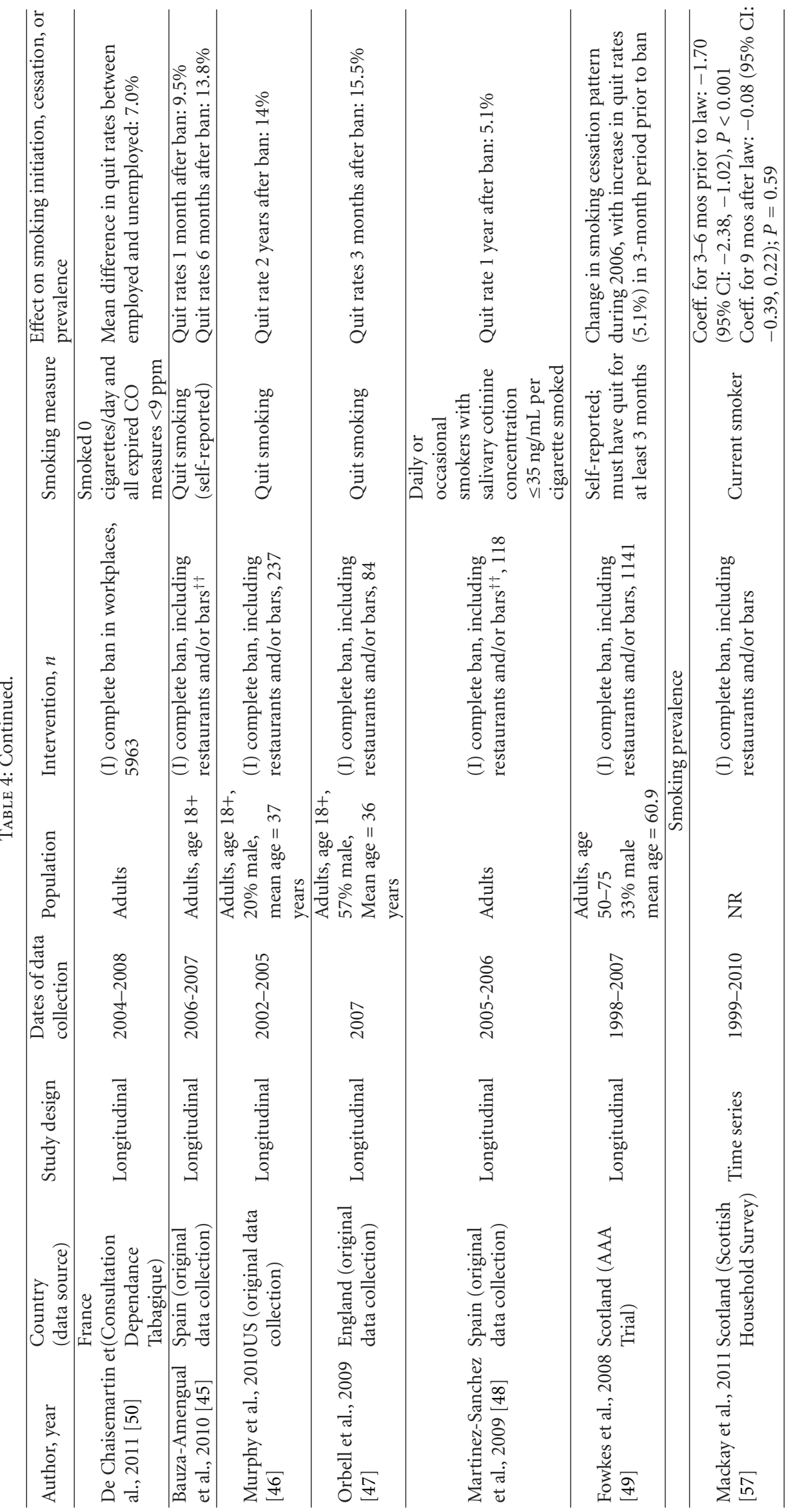




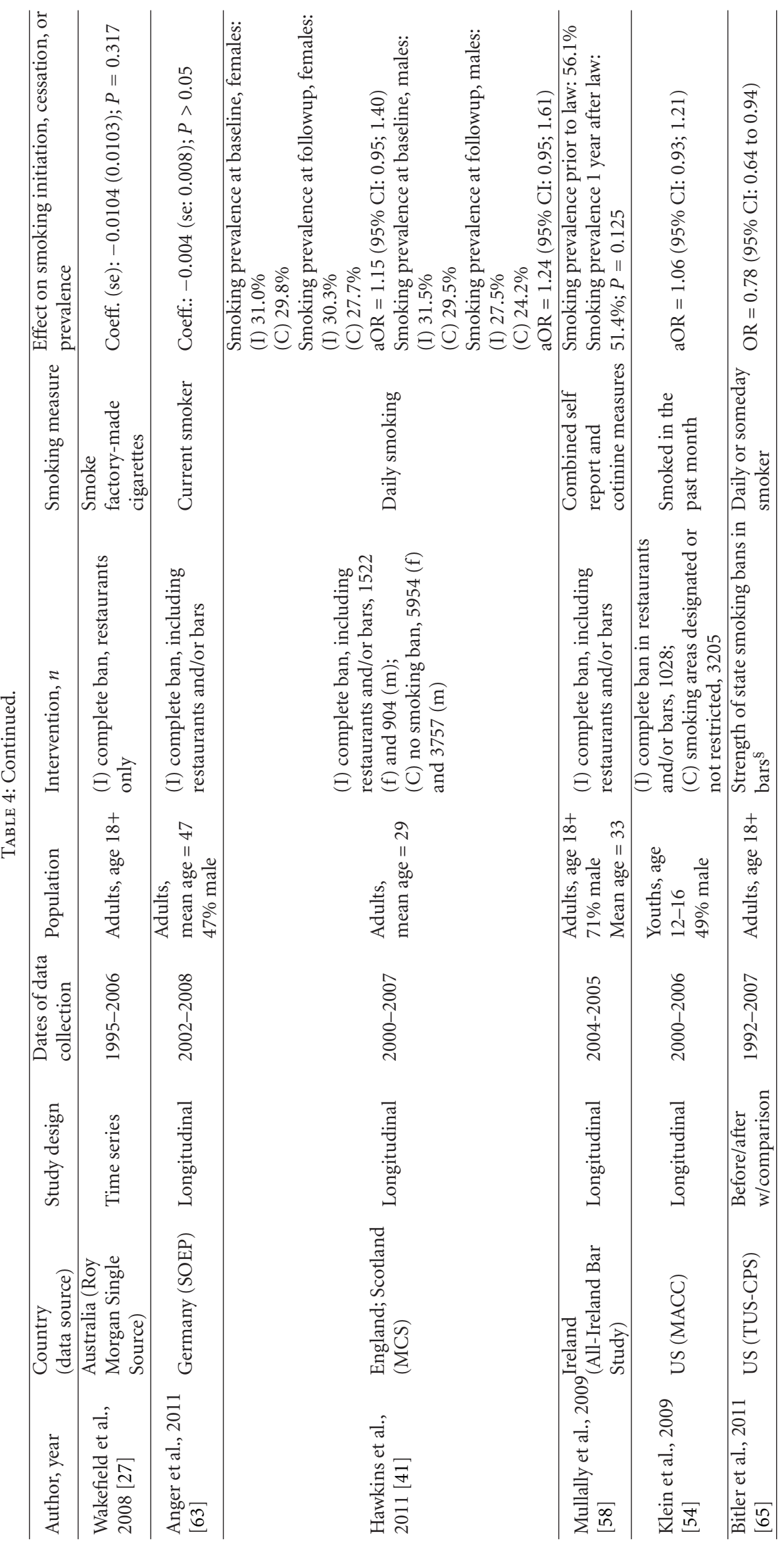




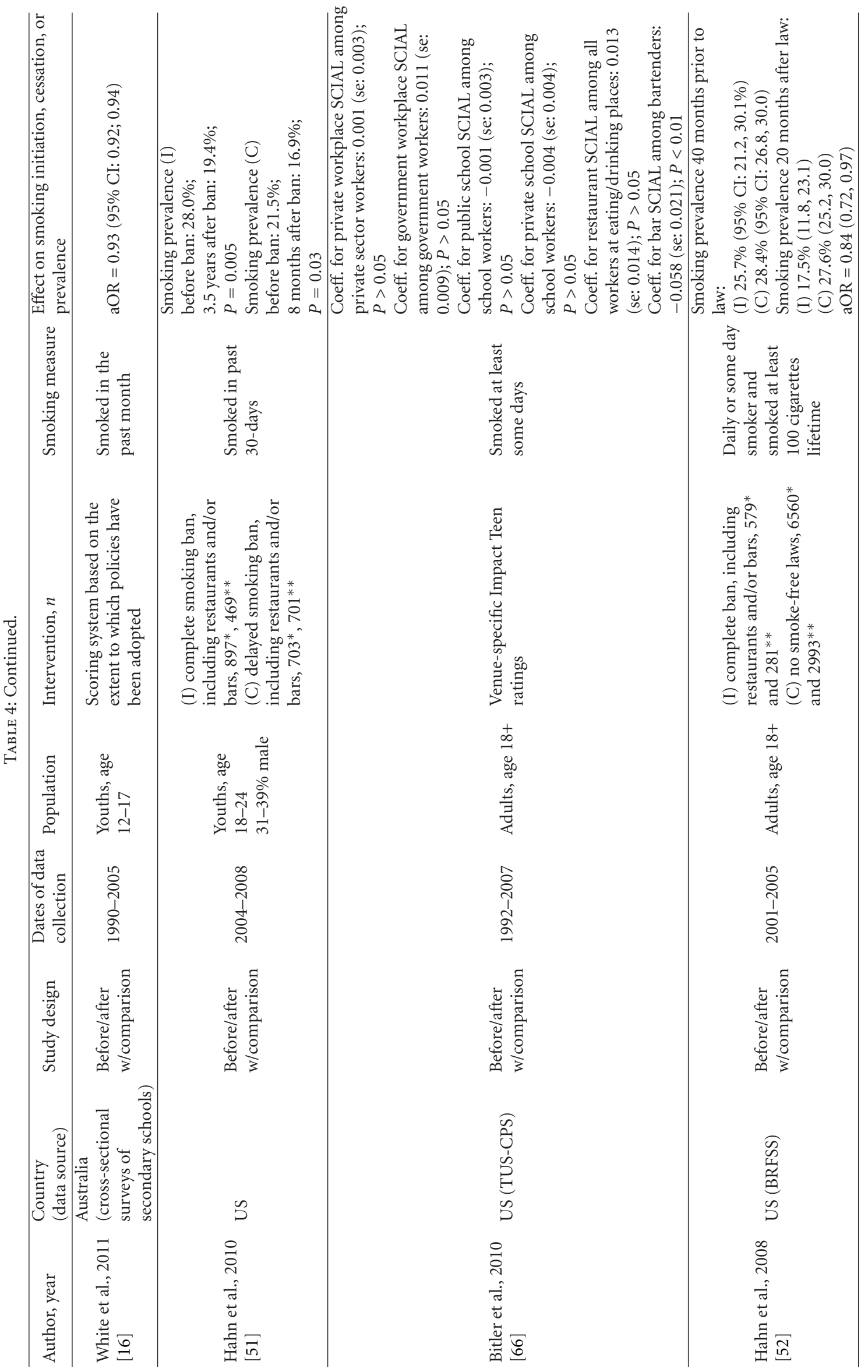




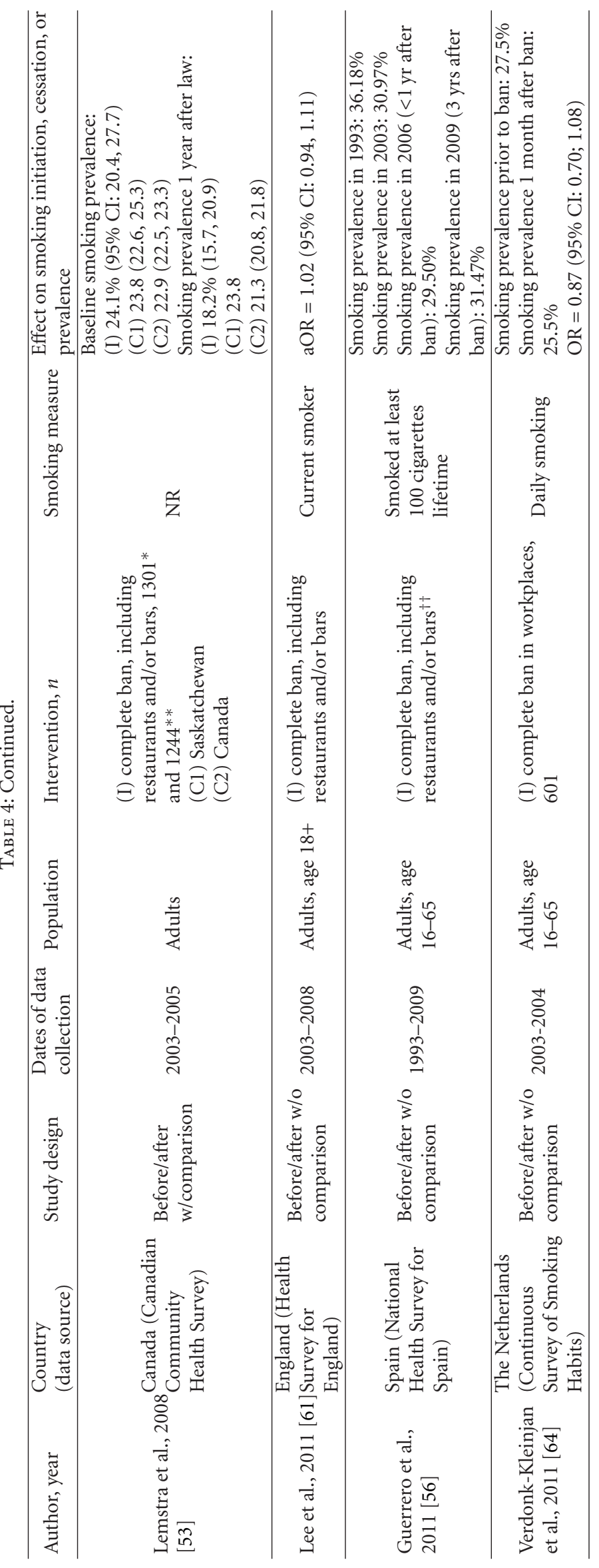




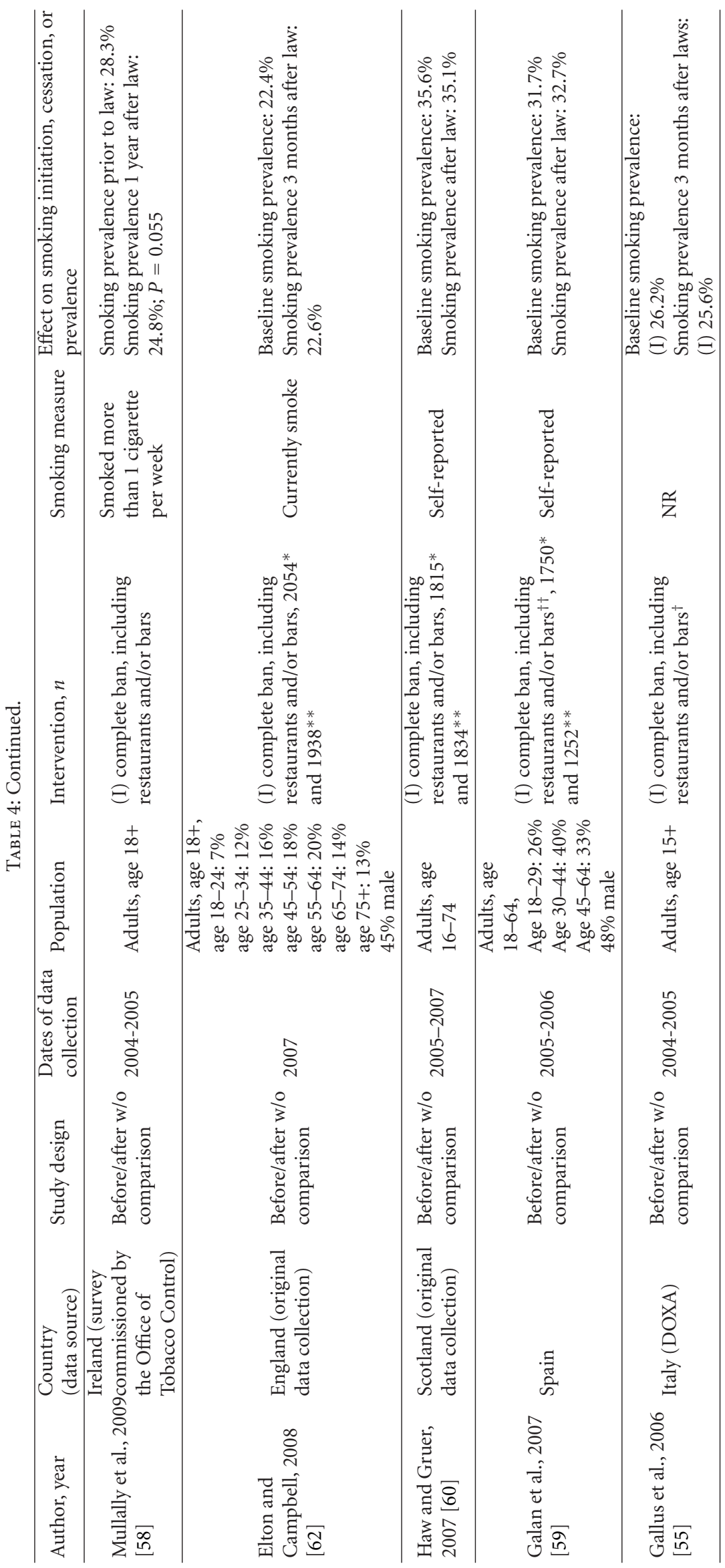




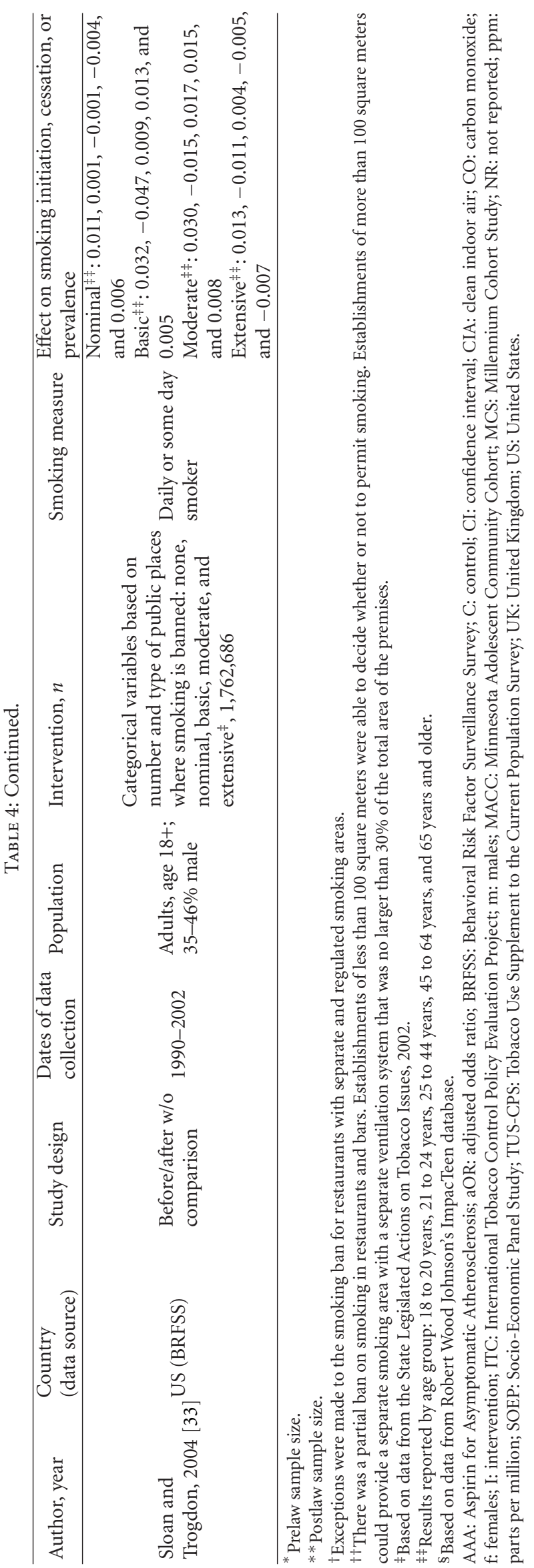


due to the small number of changes in state smoking bans during the period of their analysis.

\subsection{Banning Advertising and Sponsorship of Tobacco Products.} We found insufficient evidence to estimate the impact of implementation of advertising bans or restrictions. We did not identify any studies measuring smoking initiation or cessation as the outcome. Five studies examined prevalence (three among youths and two among adults), comparing rates of smoking before and after implementing advertising bans or restrictions (Table 5). Two of the youth studies showed declines in smoking prevalence; however, inferences regarding the independent effect of advertising bans were limited by the lack of a control group and long time frame between baseline and followup $[67,68]$. The other youth study, conducted in Australia, showed an increased smoking prevalence with stronger point-of-purchase and outdoor advertising bans, after adjusting for demographics and other tobacco control policies (adjusted odds ratio: 1.03, 95\% CI: $1.01 ; 1.05)$ [16].

Other factors influencing findings included the comprehensiveness of the ban, the level of enforcement, and industry response of shifting to indirect means of marketing. One study evaluated price and smoking prevalence in the five largest capital cities in Australia, while adjusting for a tobacco sponsorship ban that "brought two remaining states into line with the three states that had already banned tobacco sponsorship." The authors found no association between the incremental increase in coverage of the ban and prevalence, but noted that after the ban, tobacco companies shifted resources to other outlets (e.g., point of sale) [30]. One US study found that the presence of any advertising restriction at the state level was associated with a nonstatistically significant reduction in smoking prevalence [33].

3.5. Health Warning Labels. We found insufficient evidence to quantify the direct impact of health warning labels on smoking prevalence. No studies examined smoking initiation. Only four studies measured smoking prevalence or cessation, and they were typically not the primary endpoints under study (Table 6).

The limited number of studies is likely due to the fact that health warning labels are implemented at the countrylevel, and there have been only a limited number of countries introducing new or modified warning labels. In Australia, increasing the text size from $15 \%$ to $25 \%$ of pack area was associated with a quit rate of $11 \%$, but without a control group it is not possible to determine the net impact [69]. In addition to study design, heterogeneity could be expected as a result of differences in size, content, and design (e.g., text versus pictorial). Borland et al., using data from the International Tobacco Control Policy project, studied the effects of warning labels across four countries over four waves of data collection. Over this time period, the health warning labels on cigarette packs changed in UK (increasing text size and banning misleading product descriptors) and Australia (adding graphic images). However, the timing of these changes relative to data collection did not allow for direct comparisons of cessation behavior before and after implementation [70].

Two other studies evaluated the effects of health warning labels on smoking prevalence $[30,71]$. One study reported on the effects of the introduction of 6 rotating text warnings in Australia [30], while the other reported on rotating pictorial health warning labels that covered $50 \%$ of the package in Canada [71]. Neither study reported a significant decrease in smoking prevalence.

3.6. Mass Media Campaigns. We found moderate strength of evidence to quantify the independent impact of mass media campaigns. Five, eight, and eight studies examined the independent effects of a mass media campaign on initiation, cessation, and prevalence, respectively (Table 7). The findings for youths were more consistent than adults, with most studies reporting a reduction of $20 \%$ to $40 \%$ in the odds of smoking initiation [72-75].

In addition to study design, key sources of heterogeneity include differences in content, tone, channels, and reach of campaigns. For example, the two studies which examined a broad campaign focused on cardiovascular disease failed to find consistent evidence of impacts on smoking prevalence $[76,77]$. Among US youths, large-scale campaigns focused on tobacco industry manipulation and deception were shown to be effective at reducing initiation $[75,78,79]$. Smaller studies with other types of content were also shown to be effective [72-74]. Less consistent evidence is available for smoking cessation among youths and young adults [74, $80,81]$. Two studies evaluated campaigns that targeted ethnic groups. One, which targeted Spanish-speaking smokers, reported an increased 6-month abstinence rate among those who called into the quit line [82]. The other targeted youths of diverse racial and ethnic backgrounds, but did not report a significant effect on smoking prevalence [83]. Among adults, a mass media campaign focused on hard-hitting, graphic messages with sustained, and high levels of exposure was shown to effectively reduce smoking prevalence. A time series analysis of a mass media campaign in Australia found that an increase in 1,000 gross rating points (a measure of advertising reach and frequency) led to a reduction in adult smoking prevalence of $0.8 \%$ within 2 months, after controlling for price [27]. The study also found that the effects dissipated rapidly, suggesting that sustained high levels of exposure are necessary to maximize reductions in smoking prevalence.

\section{Discussion}

The purpose of this paper was to examine and quantify the independent impact of tobacco control policies on smoking behavior, as measured by initiation, cessation, or prevalence. Although tobacco control policies are often implemented in combination, we focused on studies that attempted to separate out the independent impact of each policy to better inform models for predicting smoking patterns. We also focused on studies that measured smoking behavior before and after policy implementation, to ensure that the proper temporal relationship was met. 


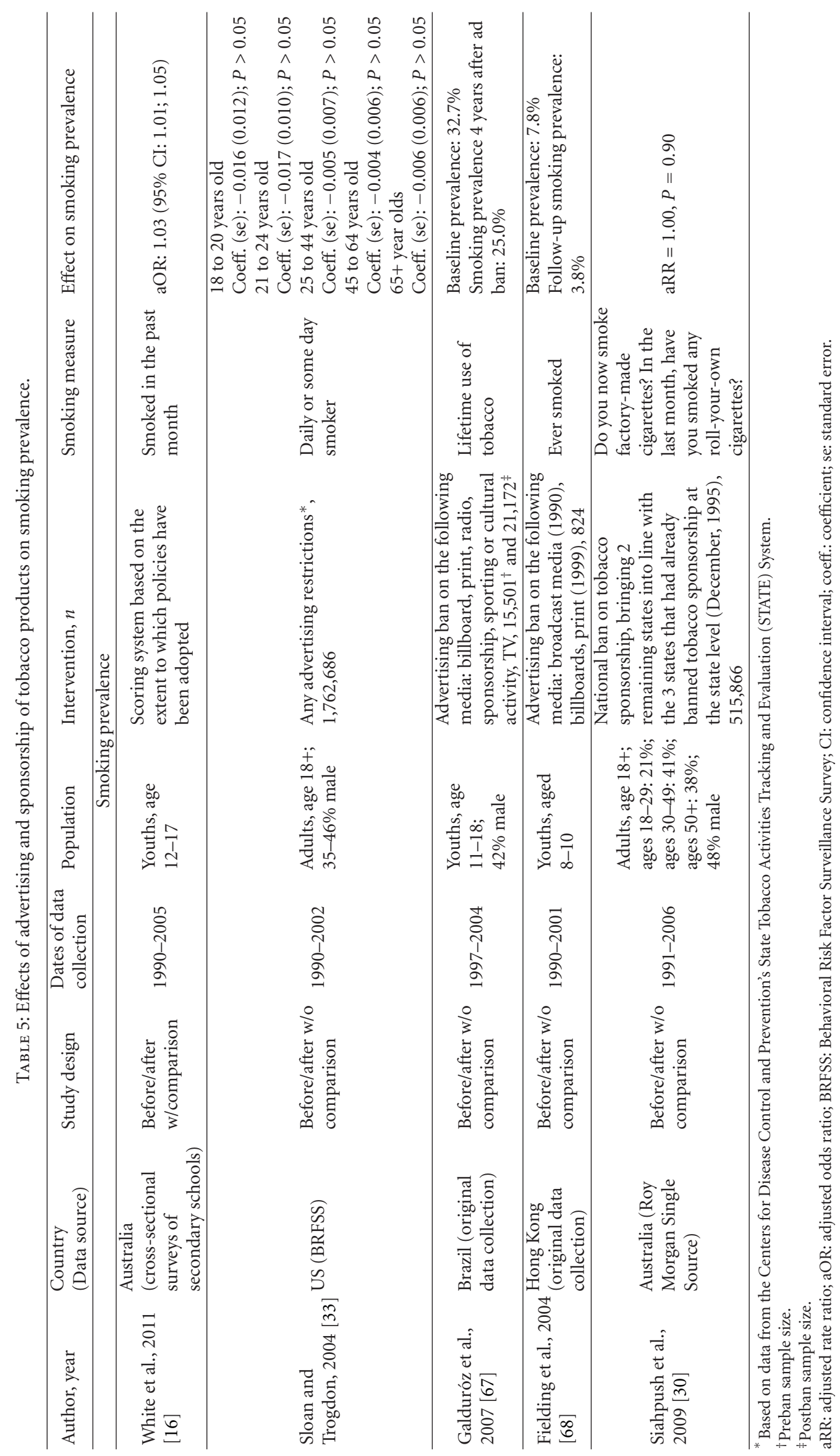




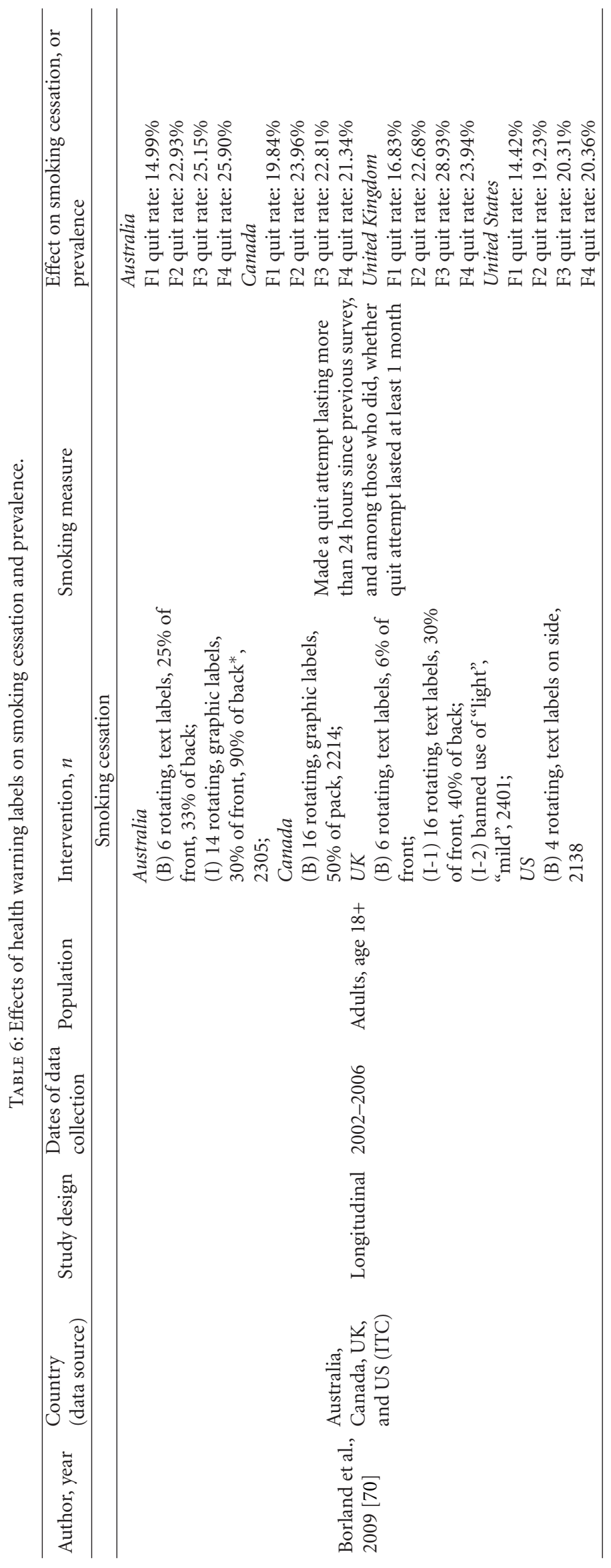




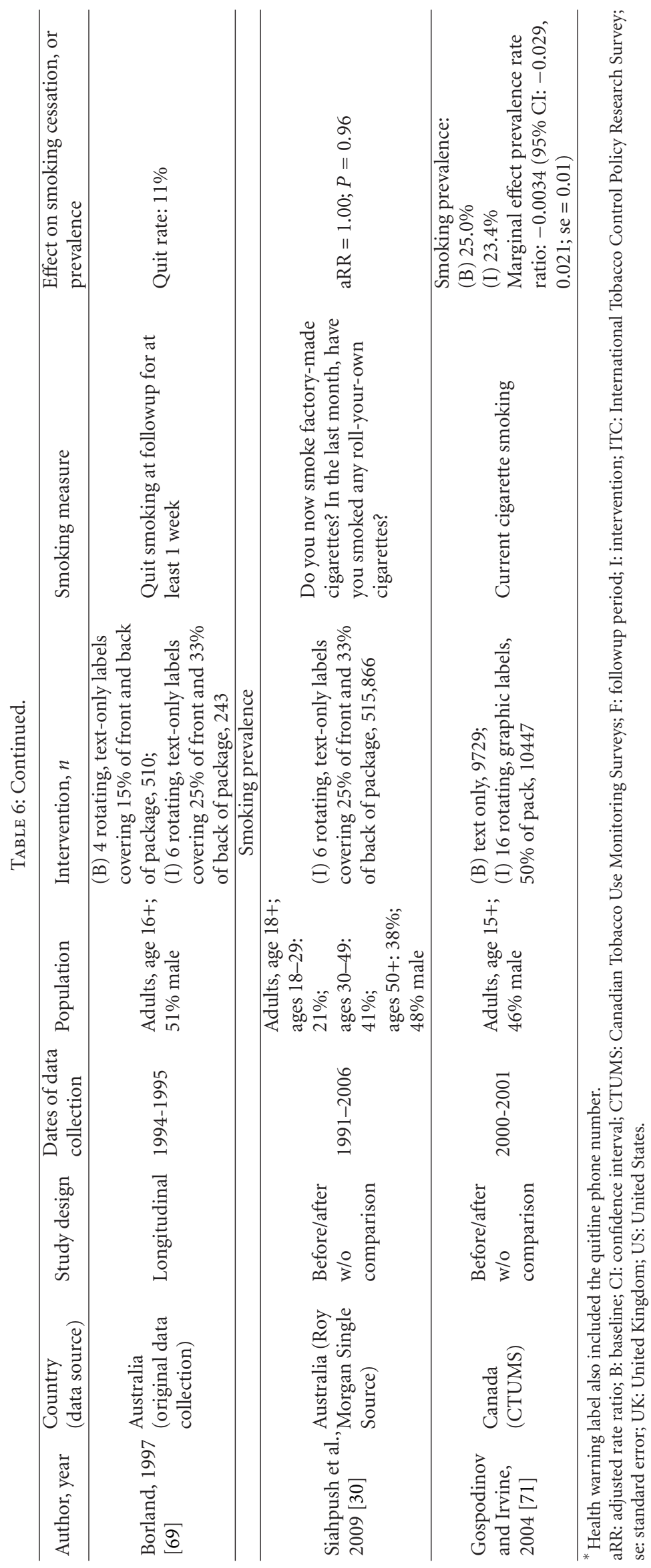




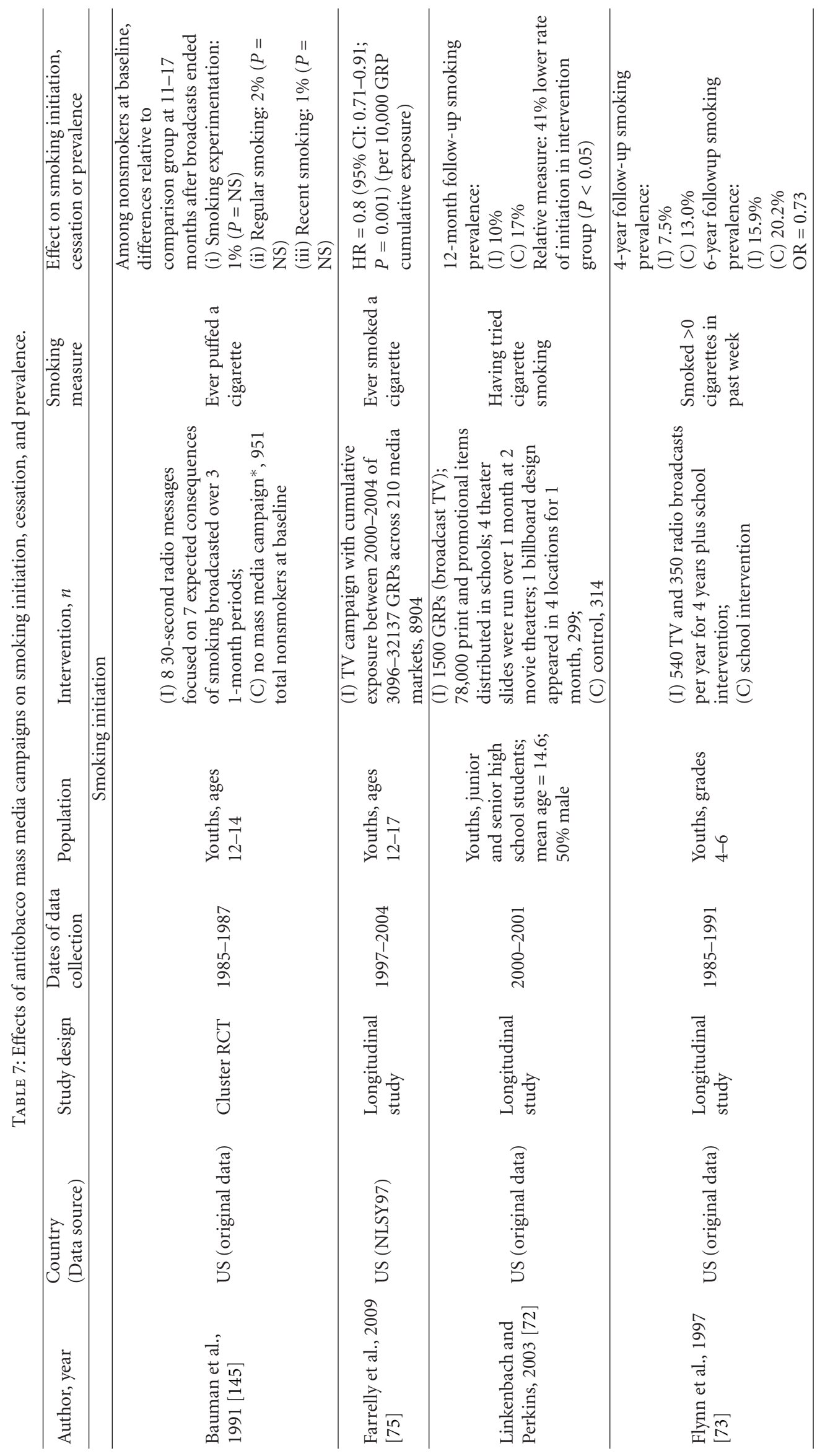




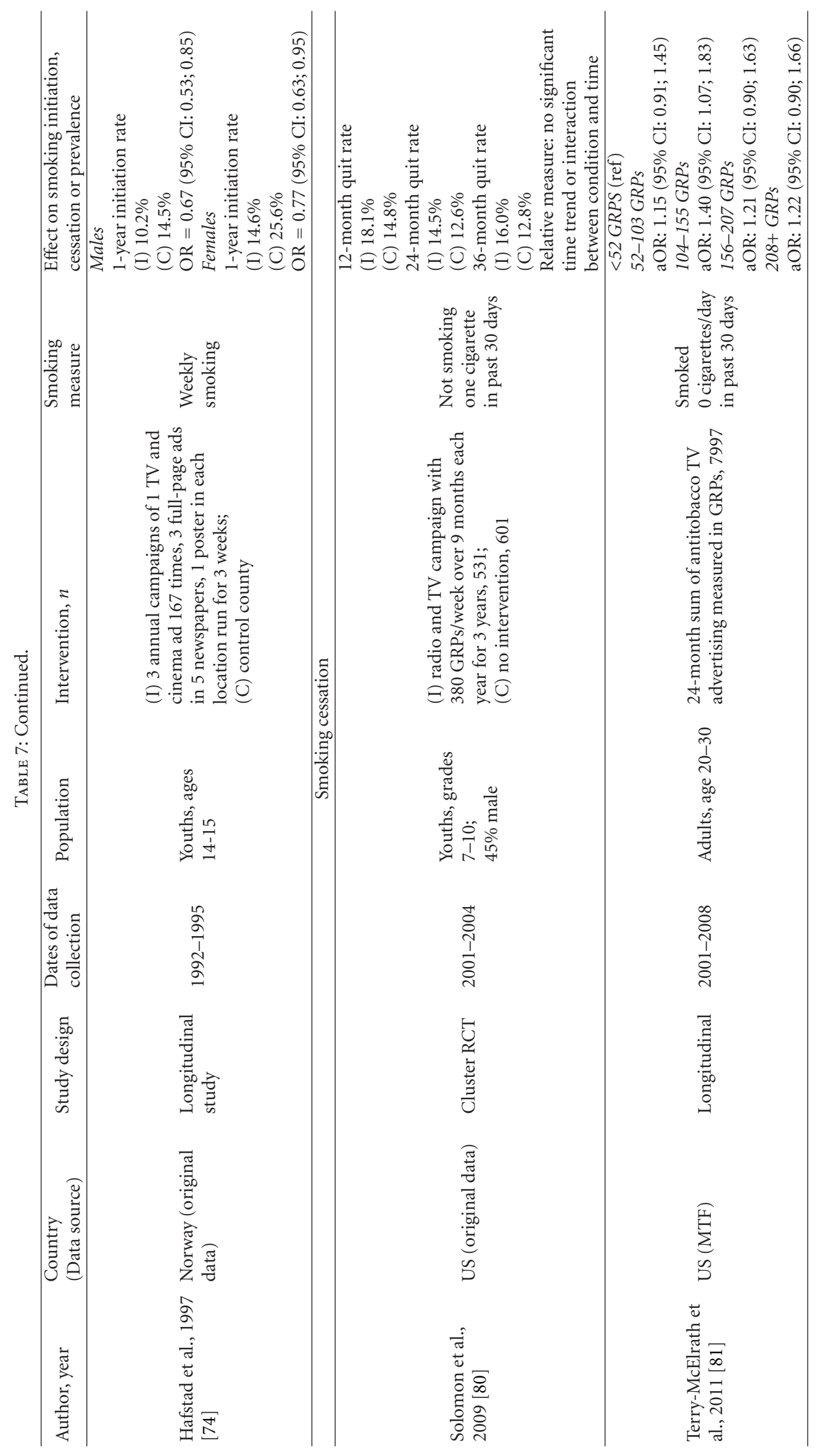




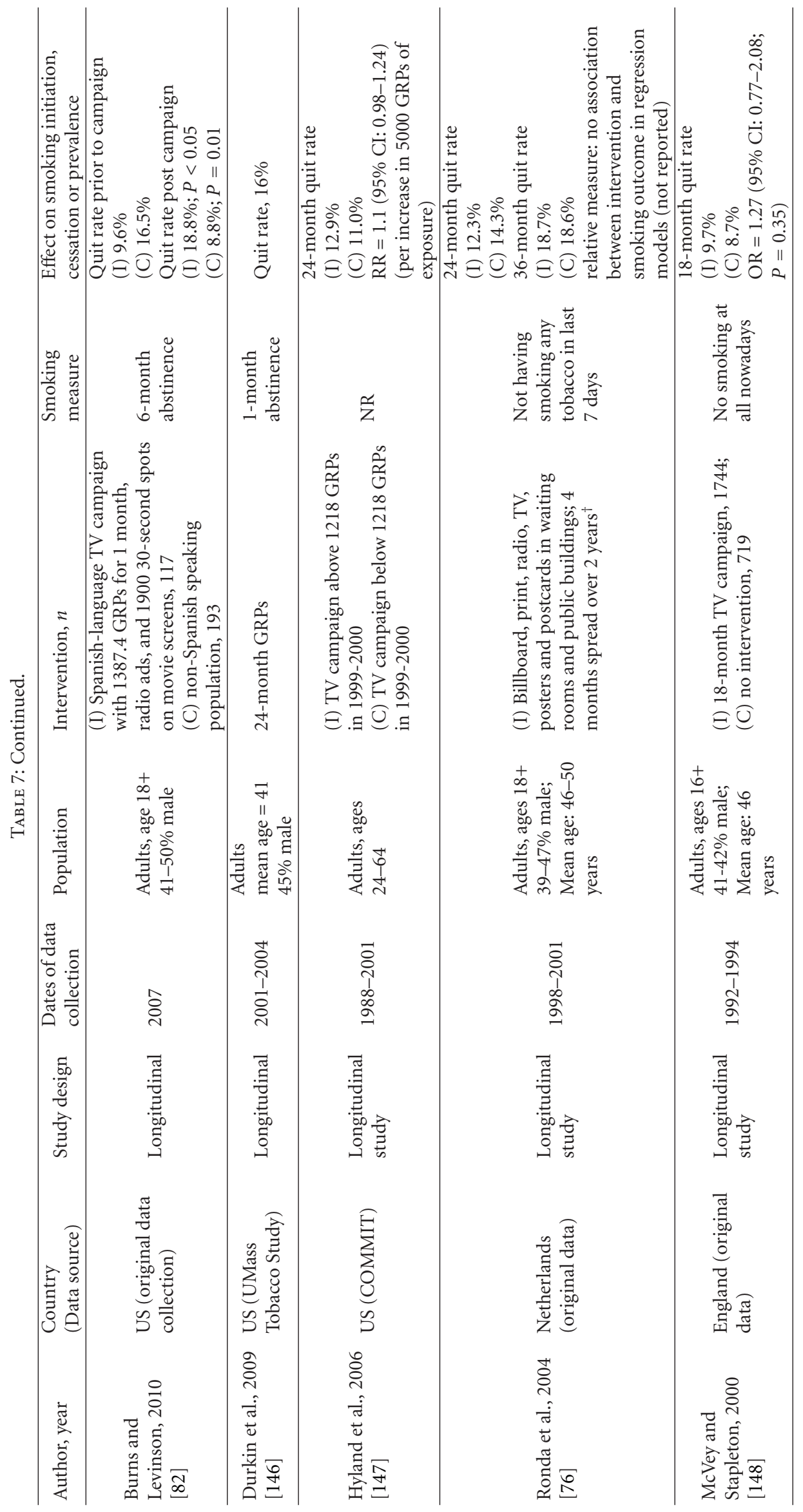




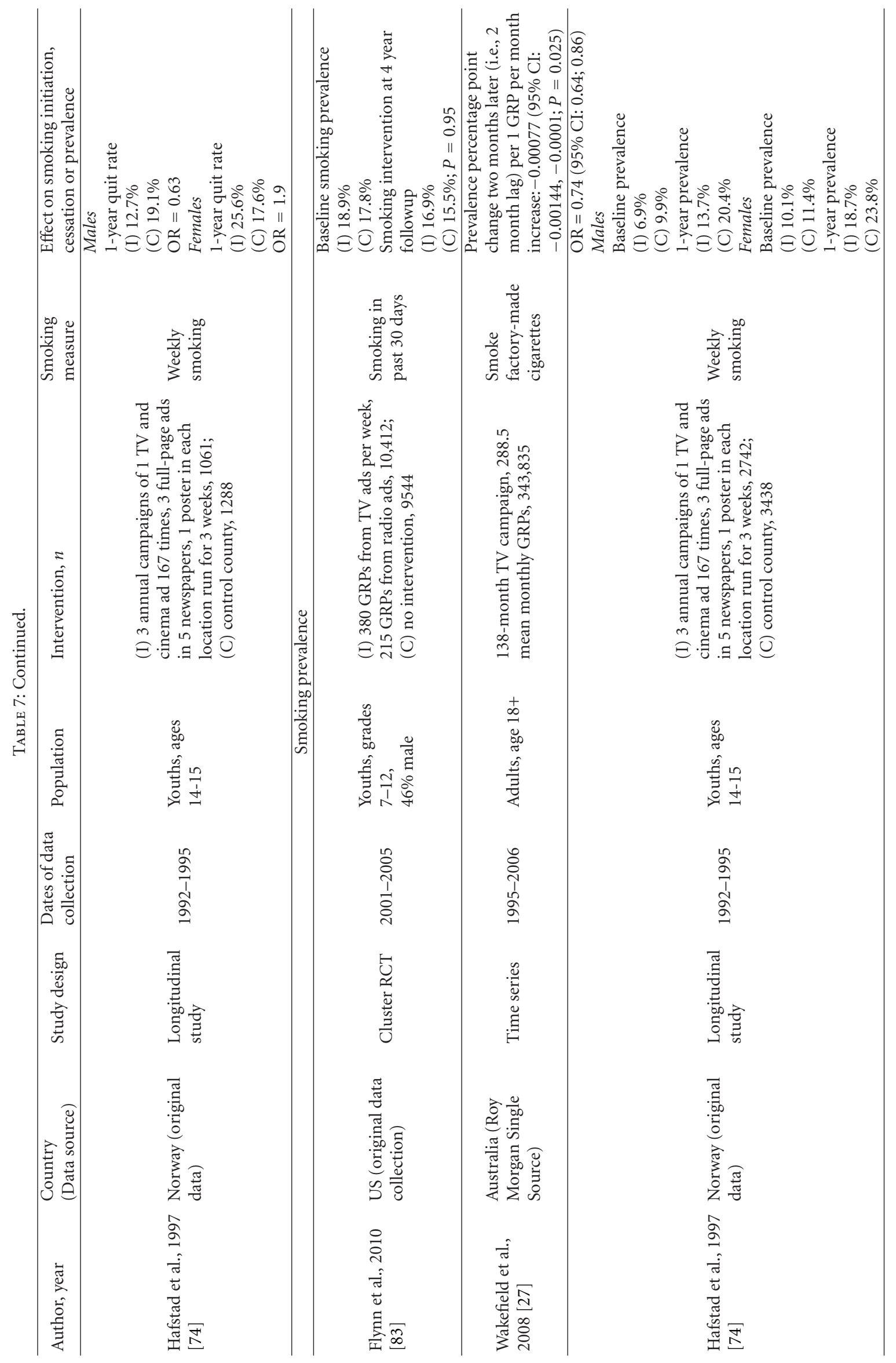




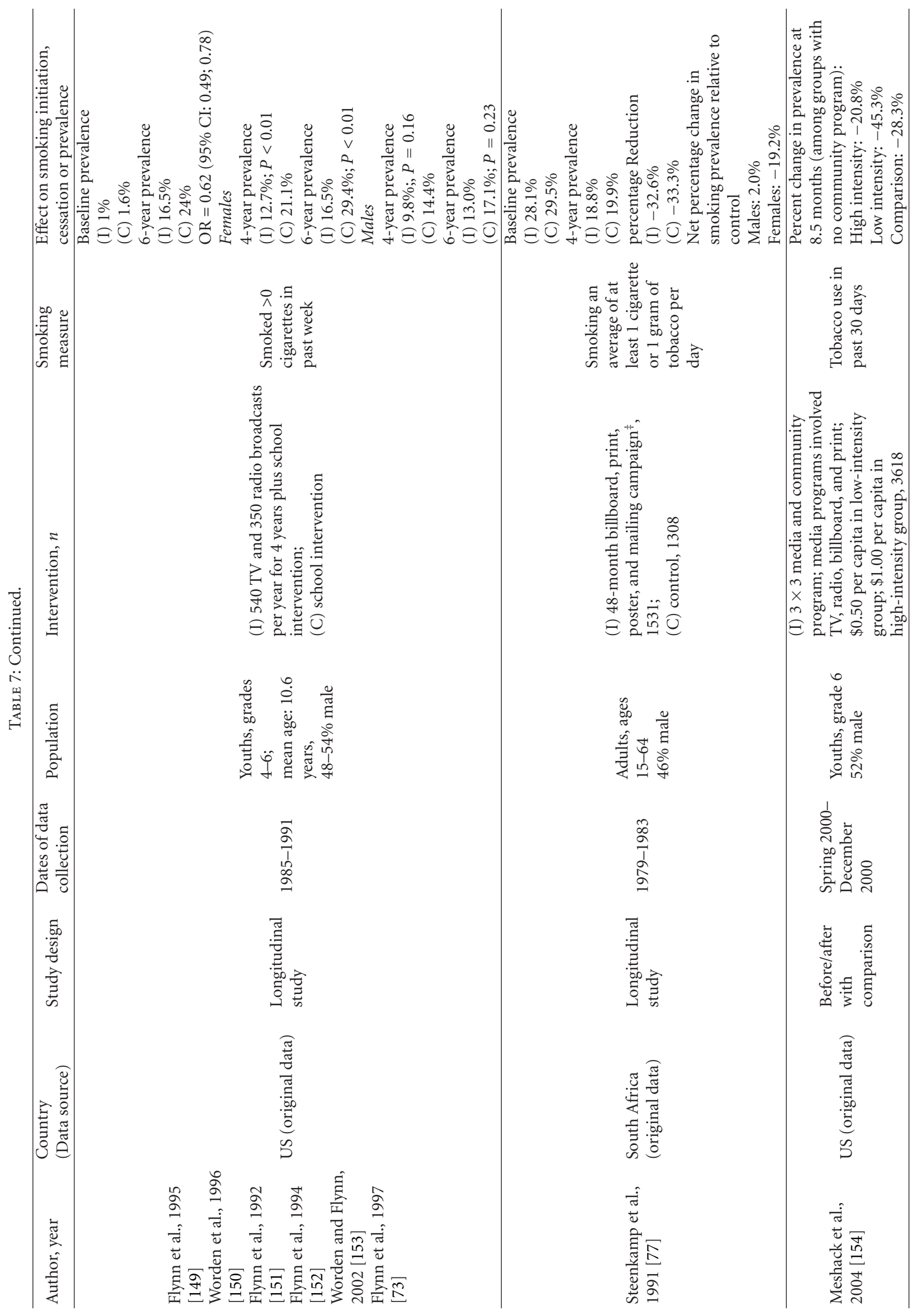




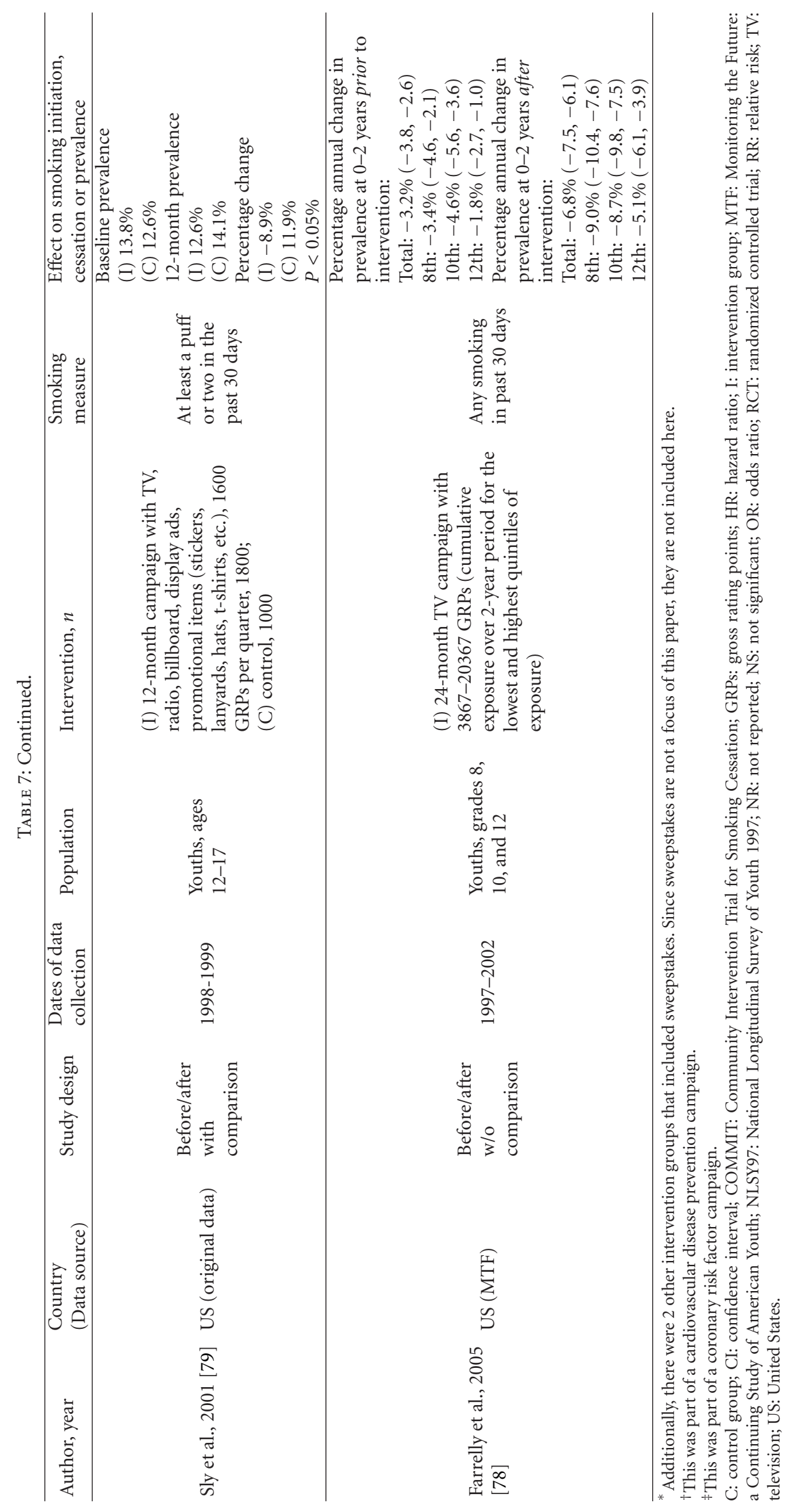


4.1. Increasing Taxes. We found evidence that increases in tobacco pricing independently reduced smoking prevalence among youths and adults. More limited data were available for low- and middle-income countries, with some studies finding an association with decreased smoking prevalence $[29,36]$ and others finding no difference $[29,39$, 84]. Another review found that low- and middle-income countries tended to be more price sensitive than highincome countries [85]. Based on tobacco consumption data (from estimates of cigarette sales), they estimated a price elasticity of demand of -0.8 for low- and middle-income countries versus -0.4 for high-income countries. Many factors contribute to the heterogeneity in findings, including cigarette affordability, product substitution due to wide price ranges, industry activity to reduce price for consumers, opportunities for tax avoidance, smuggling, and smokers' level of addiction.

4.2. Banning Smoking in Public Places. We found evidence that smoking bans can have an impact on prevalence in the general population, with greater reductions found in smaller geographic areas with limited previous legislation, compared with studies conducted at the national level. Smoking bans likely impact general population behaviour through reducing smoking opportunities and denormalizing smoking [86]. The timing of a smoking ban relative to the underlying tobacco control environment may influence its effectiveness. For example, in settings with limited tobacco control activities, the implementation of a comprehensive ban may trigger a greater shift in social norms. In other settings, implementation may represent an incremental change in the coverage of smoke-free places after years of social norm change and prevalence declines. Different impacts on smoking behaviour would be expected under these scenarios. The effectiveness of a smoking ban also depends on the strength of prior legislation, comprehensiveness of legislation, level of enforcement, and public support [87]. Public support tends to be high and increases after implementation [86].

The International Agency for Research on Cancer (IARC) found sufficient or strong evidence that smokefree workplaces reduce cigarette consumption and increase cessation rates and that smoke-free policies reduce youth tobacco use [86]. The authors also concluded that a greater decline in smoking could be expected when the policy was part of a comprehensive tobacco control program. In the present paper, we excluded studies that examined specific workplace policies on employee behavior, in order to estimate impacts across the entire population. The studies in the IARC review were all conducted in high-income countries. With the increased adoption of smoking bans in low- and middle-income countries, more evaluation is needed.

4.3. Banning Advertising and Sponsorship of Tobacco Products. We found insufficient evidence to estimate the direct impact of advertising bans or restrictions on smoking initiation, cessation, or prevalence in the general population. The youth studies suggest that advertising bans may play a role in reducing smoking; however, methodological limitations restrict inferences that can be drawn.

Despite limited direct evidence of the impact of advertising bans, the role of tobacco advertising on smoking initiation is well established [88-91]. Advertising increases positive user imagery of tobacco, distorts the utility of tobacco use, increases curiosity about tobacco use [91], and influences normative beliefs and perceptions of tobacco use prevalence [92], all predictive of future smoking experimentation. Youth exposure to tobacco marketing has been associated with a doubling of the chances of initiation [93]. Comprehensive bans are the only effective way to eliminate tobacco marketing exposure, as the tobacco industry subverts restrictions by substituting marketing channels are not covered by existing laws [94].

4.4. Health Warning Labels. We found insufficient evidence describing the direct impact of introducing or strengthening cigarette warning labels on smoking initiation, cessation, or prevalence. The few studies that were identified were not designed specifically to address the impact of warning labels on these outcomes.

Cigarette health warning labels are a means for delivering messages about health risks from smoking and resources for obtaining help to quit. Warning labels can be implemented with little cost to governments, in comparison with mass media campaigns $[95,96]$. Despite the limited direct evidence, indirect evidence describes the impact of warning messages on knowledge, salience, and cognitive processing (reading, thinking about, and discussing the warning labels) and the association between these intermediate outcomes and quit intentions, quit attempts, or cessation behavior [97]. Health warnings increase knowledge of health effects $[95,98]$ and have been cited as a motivating factor among quitters [99]. Studies evaluating graphic, pictorial warning labels in Canada and Australia have shown high levels of cognitive processing $[96,98,100]$ and an association between cognitive processing and quitting intention and behavior $[70,98,100,101]$. In Malaysia, a country with small, textbased warnings, a cross-sectional association was observed between cognitive processing of warning labels and intention to quit and self-efficacy among male smokers [102]. These studies provide indirect evidence for a role of health warning labels in smoking behavior.

4.5. Mass Media Campaigns. We found evidence that mass media campaigns can have an independent effect on reducing initiation of smoking in youths and prevalence in adults [73-75]. Differences observed in the impact of mass media campaigns are likely due, in part, to differences in content, tone, and reach. Although it is not clear which types of messages work best, behavioral research has suggested that adult audiences are most likely to respond to graphic depictions of the health consequences of smoking, and that youth audiences are more likely to respond to messages about tobacco industry deception and manipulation [103105]. Conversely, messages focusing on smoking as an adult 
choice, commonly used in tobacco industry sponsored campaigns, have been shown to be ineffective or even increase youth tobacco use $[103,104,106]$. Campaign messages need to be sufficiently funded to ensure enough exposure [103, $104]$, tailored to the audience, and varied and rotated to keep them salient $[88,104,105]$.

Our findings are consistent with prior evidence. A recent National Cancer Institute monograph concluded that mass media campaigns, even those independent of other community-wide programs, are effective at reducing smoking prevalence [103]. Several reviews have concluded that mass media campaigns are effective in reducing youth tobacco use, specifically when combined with other tobacco control programs [104, 107]. A Cochrane review, however, concluded that tobacco control programs with mass media components can be effective in reducing adult smoking, but the evidence is based on studies of "variable quality" and the "specific contribution of the mass media component is unclear" [108].

4.6. Limitations. Our paper had several limitations. First, we only included studies that evaluated the independent impact of a policy or intervention, thereby excluding studies of multicomponent tobacco control programs. Many studies have demonstrated the effectiveness of multicomponent tobacco control programs [109-111]. Policies are most often implemented in combination with others. Even if they are not implemented on the same date, it is often not possible to analytically separate out their independent contributions. However, evaluation of multicomponent interventions inherently captures the potential synergistic or duplicative effects of policies implemented in combination and provides a range of achievable impacts at the population level.

By limiting our paper to the effects of tobacco control interventions on smoking prevalence, initiation, and cessation, we excluded several other intermediate outcomes, such as tobacco consumption. Tobacco consumption data (i.e., cigarette sales data) is routinely collected in many countries, whereas prevalence data requires conducting surveys. Many studies have demonstrated that increased tobacco prices lead to lower per capita cigarette consumption in low-, medium-, and high-income countries [94, 112-142]. Additionally, studies evaluating per capita consumption have generally found an association between comprehensive advertising bans and reduced cigarette consumption in both developed and developing countries [94, 126]. Including tobacco consumption, data could have strengthened our conclusions on the effectiveness of these interventions. However, tobacco consumption data does not allow us to distinguish between reduced smoking prevalence and reduced consumption among smokers. Policies and interventions can affect outcomes beyond smoking behavior [143]. As mentioned earlier, health warning labels can impact on knowledge, salience, and cognitive processing, which can influence behavior. Inclusion of these other outcomes could have strengthened our results.

Many tobacco control interventions affect entire communities or countries. Complex social and cultural contexts often limit the ability to identify comparable groups of individuals or regions of study. As a result, comparison groups may vary on characteristics related to smoking behavior in the population [103]. In the absence of comparable control groups, time series or pre-/post- studies provide useful evidence for effectiveness. Information on prior trends is preferred to a single estimate before and after an intervention [103], but this requires rich surveillance data which may not be available in all settings. In longitudinal studies, participant attrition leads to the potential for selection bias and a reduction in statistical power.

Most studies included in this paper were from highincome countries, in part because they are more likely to have implemented policies. However, they may not necessarily predict the impact in low- and middle-income countries. With global expansion of tobacco control efforts through the FCTC, a wide range of programs and policies are being implemented across the world. Rigorous evaluation of these programs is needed to determine the effectiveness in reducing tobacco use. Previous studies have suggested that lower income populations may be more sensitive to demandside tobacco control activities. For example, it is well established that low-income populations are more sensitive to changes in price [85]. In addition, Blecher found a greater association between strength of advertising bans and per capita cigarette consumption in developing compared with developed countries [126]. The author suggested that the lower level of awareness of tobacco-related harm increases the public's susceptibility to tobacco marketing. Similarly, introduction of health warning labels may have a greater impact in settings with fewer other sources of antitobacco information. In addition, implementation of smoking bans could produce a greater change in social norms than in settings, where smoking has been declining for years due to concerted tobacco control efforts.

\section{Conclusion/Recommendations}

Estimates of the impact of tobacco control policies are critical for setting achievable targets for reductions in smoking prevalence. For several of the policies, we found high or moderately strong evidence that these interventions can independently reduce smoking prevalence in the general population. However, a wide range of impacts were observed. Factors influencing the observed impact likely include the strength of the policy and level of enforcement; promotion around its implementation; the content, tone, and reach of a mass media campaign; the underlying tobacco control environment; strategic activities of the tobacco industry to dampen the effect of policies and programs. Future studies should attempt to characterize these factors to understand the variation in impacts.

Simulation models should account for this uncertainty by incorporating sensitivity analyses or probabilistic approaches to evaluate a possible range of effectiveness. For some policies, indirect evidence can be incorporated with simplifying assumptions, such as studies using per capita consumption or shorter-term outcomes that have 
been shown to predict subsequent smoking behavior change. Finally, given the number of studies evaluating comprehensive, multicomponent programs, models could be developed to incorporate this evidence, rather than assuming that individual interventions implemented in combination will act independently. Any approach to predict future smoking patterns will require some simplifying assumptions, but modeling can provide critical tools to inform decisionmaking and priority setting and to set realistic goals for reducing smoking prevalence and improving public health.

\section{Appendix}

\section{PubMed Search Strategies}

The following Search Strings were used.

Search Number 1. (("Smoking/epidemiology"[mh] OR "Smoking/prevention and control" $[\mathrm{mh}]$ OR "Smoking/economics"[mh] OR smoking[tiab] OR smoker*[tiab] OR smoked[tiab] OR cigarette*[tiab] OR tobacco[tiab] OR cigar[tiab] OR bidi*[tiab] OR hooka*[tiab] OR waterpipe*[tiab] OR kretek*[tiab] OR shisha*[tiab]) AND (price[tiab] OR prices[tiab] OR tax[tiab] OR taxes[tiab] OR taxation[tiab])) NOT (animals[mh] NOT humans[mh]).

Search Number 2. (("Smoking/epidemiology"[mh] OR "Smoking/prevention and control" [mh] OR "Smoking/ psychology" [mh] OR "Smoking/legislation and jurisprudence"[mh] OR smoking[tiab] OR smoker*[tiab] OR smoked[tiab] OR cigarette*[tiab] OR tobacco[tiab] OR cigar*[tiab] OR bidi*[tiab] OR hooka*[tiab] OR

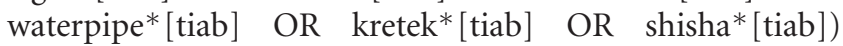
AND (()bars[tiab] OR pubs[tiab] OR (employee* [tiab] AND (polic* [tiab] OR program*[tiab])) OR indoor* [tiab] OR restaurant* [tiab] OR workplace* $[$ tiab] OR workplace* $^{*}$ tiab] OR office*[tiab] OR hospital*[tiab]) AND (smoke-free[tiab] OR smokefree[tiab] OR "smoke free"[tiab] OR anti-smoking[tiab] OR antismoking[tiab] OR no-smoking[tiab] OR "no smoking"[tiab] OR nonsmoking[tiab] OR nonsmoking[tiab] OR (smoking[tiab] AND employee*[tiab]) OR ban[tiab] OR bans[tiab] OR banning[tiab] OR law[tiab] OR legislation[tiab] OR prohibiti*[tiab] OR "smoking restriction"[tiab] OR "smoking restrictions"[tiab] OR "tobacco restriction"[tiab] OR ordinance*[tiab])) OR ((smoke-free[tiab] OR smokefree[tiab] OR "smoke free" [tiab] OR antismoking[tiab] OR antismoking[tiab] OR no-smoking[tiab] OR “no smoking”[tiab] OR non-smoking[tiab] OR nonsmoking[tiab] OR “smoking ban" [tiab] OR "smoking bans"[tiab]) AND (ban[tiab] OR bans[tiab] OR banning[tiab] OR law[tiab] OR legislation[tiab] OR prohibiti*[tiab] OR "smoking restriction"[tiab] OR "smoking restrictions" [tiab] OR ordinance* $[$ tiab])))) NOT (animals[mh] NOT humans[mh]).

Search Number 3. (("Smoking/epidemiology"[mh] OR "Smoking/prevention and control" [mh] OR "Smoking/ psychology"[mh] OR "Smoking/legislation and jurisprudence"[mh] OR smoking[tiab] OR smoker*[tiab] OR smoked[tiab] OR cigarette*[tiab] OR tobacco[tiab] OR cigar*[tiab] OR bidi*[tiab] OR hooka*[tiab] OR

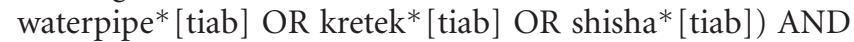
((advertis* [tiab] OR brand*[tiab] OR marketing[tiab] OR ordinance* $^{*}[\mathrm{tiab}]$ OR message*[tiab] OR television[tiab] OR tv[tiab] OR televised[tiab] OR “motion pictures"[tiab] OR radio[tiab] OR newspaper* [tiab] OR movie* [tiab] OR "in-store"[tiab] OR “in store"[tiab] OR magazine*[tiab] OR email[tiab] OR "e-mail”[tiab] OR internet[tiab] OR web[tiab] OR print[tiab] OR campaign*[tiab] OR commercial[tiab] OR commercials* [tiab] OR ((display[tiab] OR displays[tiab]) AND (retail[tiab] OR store[tiab] OR "point of purchase" [tiab] OR "point-of-purchase" [tiab OR "point of sale" [tiab] OR "point-of-sale"[tiab] OR "selfservice" [tiab] OR "self service" [tiab] OR "self-serve" [tiab] OR "self serve" [tiab])) OR sponsor*[tiab]) AND ((adolescent* [tiab] OR children[tiab] OR minor*[tiab] OR teenager*[tiab] OR teens[tiab] OR "under-age"[tiab] OR young[tiab] OR youth*[tiab] OR kids[tiab]) OR (ban[tiab] OR bans[tiab] OR banning[tiab] OR law[tiab] OR laws[tiab] OR legislation*[tiab] OR sale[tiab] OR sales[tiab] OR purchas*[tiab] OR initiat*[tiab] OR behav*[tiab] OR restrict*[tiab] OR forbid*[tiab] OR prohibit* $[$ tiab])))) NOT (animals[mh] NOT humans[mh]).

Search Number 4. (("Smoking/epidemiology"[mh] OR "Smoking/prevention and control" [mh] OR "Smoking/ psychology" $[\mathrm{mh}] \quad$ OR "Smoking/legislation and jurisprudence"[mh] OR smoking[tiab] OR smoker*[tiab] OR smoked[tiab] OR cigarette*[tiab] OR tobacco[tiab] OR cigar*[tiab] OR bidi*[tiab] OR beedi*[tiab] OR hooka*[tiab] OR waterpipe*[tiab] OR kretek*[tiab] OR shisha*[tiab] OR chutta*[tiab] OR dhumti*[tiab] OR hookli*[tiab] OR chillum*[tiab]) AND ((health[tiab] AND (warning*[tiab] OR label*[tiab])) OR (warning*[tiab] AND label*[tiab]) OR ((mild[tiab] OR light[tiab] OR "low tar" [tiab]) AND (packs[tiab] OR packet*[tiab] OR package*[tiab] OR label*[tiab])) OR (("mass media”[tiab] OR television[tiab] OR tv[tiab] OR televised[tiab] OR “motion pictures"[tiab] OR radio[tiab] OR newspaper*[tiab] OR movie*[tiab] OR "instore"[tiab] OR “in store"[tiab] OR magazine*[tiab] OR email[tiab] OR "e-mail"[tiab] OR internet[tiab] OR web[tiab] OR print[tiab] OR advertis*[tiab] OR campaign* [tiab] OR promotion* [tiab] OR marketing[tiab] OR commercial*[tiab] OR packs[tiab] OR package*[tiab] OR packet*[tiab]) AND (initiat*[tiab] OR cessation[tiab] OR quit[tiab] OR quitting[tiab] OR stop[tiab] OR stopping[tiab] OR antismoking[tiab] OR “anti-smoking”[tiab] OR antitobacco[tiab] OR antitobacco[tiab])))) NOT (animals[mh] NOT humans[mh]).

Search Number 5. Number 1 OR Number 2 OR Number 3 OR Number 4. 


\section{Conflict of Interests}

The authors declare that they have no conflict of interests.

\section{Authors' Contribution}

E. A. Tang, G. Chander, H. E. Hutton, O. A. Odelola, J. L. Elf, B. M. Heckman-Stoddard, E. B. Bass, E. A. Little, and E. B. Haberl B. J. Apelberg contributed equally to this paper.

\section{Acknowledgments}

The authors would like to thank Jennifer Ellis for her review and comment. This paper was funded by Bloomberg Philanthropies through the International Union Against Tuberculosis and Lung Disease.

\section{References}

[1] C. D. Mathers and D. Loncar, "Projections of global mortality and burden of disease from 2002 to 2030," PLoS Medicine, vol. 3, no. 11, pp. 2011-2030, 2006.

[2] P. Jha, M. K. Ranson, S. N. Nguyen, and D. Yach, "Estimates of global and regional smoking prevalence in 1995, by age and sex," American Journal of Public Health, vol. 92, no. 6, pp. 1002-1006, 2002.

[3] A. D. Lopez, N. E. Collishaw, and T. Piha, "A descriptive model of the cigarette epidemic in developed countries," Tobacco Control, vol. 3, pp. 242-247, 1994.

[4] World Health Organization, "WHO Framework Convention on Tobacco Control," 2009, http://www.who.int/fctc/about/ en/index.html.

[5] World Health Organization, WHO Report on the Global Tobacco Epidemic, 2008: The MPOWER Package, World Health Organization, Geneva, Switzerland, 2008.

[6] Agency for Healthcare Research and Quality, "Methods Guide for Effectiveness and Comparative Effectiveness Reviews," Agency for Healthcare Research and Quality Rockville, Md, USA, AHRQ Publication No. 10(11)EHC063-EF, March 2011, http://www.effectivehealthcare. ahrq.gov/methodsguide.cfm.

[7] J. M. Nonnemaker and M. C. Farrelly, "Smoking initiation among youth: the role of cigarette excise taxes and prices by race/ethnicity and gender," Journal of Health Economics, vol. 30, no. 3, pp. 560-567, 2011.

[8] A. Sen and T. Wirjanto, "Estimating the impacts of cigarette taxes on youth smoking participation, initiation, and persistence: empirical evidence from Canada." Health Economics, vol. 19, no. 11, pp. 1264-1280, 2010.

[9] J. Cawley, S. Markowitz, and J. Tauras, "Lighting up and slimming down: the effects of body weight and cigarette prices on adolescent smoking initiation," Journal of Health Economics, vol. 23, no. 2, pp. 293-311, 2004.

[10] J. A. Tauras, "Can public policy deter smoking escalation among young adults?" Journal of Policy Analysis and Management, vol. 24, no. 4, pp. 771-784, 2005.

[11] P. DeCicca, D. Kenkel, and A. Mathios, "Putting out the fires: will higher taxes reduce the onset of youth smoking?" Journal of Political Economy, vol. 110, no. 1, pp. 144-169, 2002.

[12] J. A. Tauras and F. J. Chaloupka, "Determinants of smoking cessation: an analysis of young adult men and women," NBER Working Paper No. 7262, 1999.
[13] M. Grossman, "Individual behaviours and substance use: the role of price.," Advances in Health Economics and Health Services Research, vol. 16, pp. 15-39, 2005.

[14] J. A. Tauras and F. J. Chaloupka, "Price, clean indoor air, cigarette smoking: evidence from longitudinal data for young adults," NBER Working Paper No. 6937, 1999.

[15] D. Kostova, H. Ross, E. Blecher, and S. Markowitz, "Is youth smoking responsive to cigarette prices? Evidence from lowand middle-income countries," Tobacco Control, vol. 20, pp. 419-424, 2011.

[16] V. M. White, C. D. Warne, M. J. Spittal, S. Durkin, K. Purcell, and M. A. Wakefield, "What impact have tobacco control policies, cigarette price and tobacco control programme funding had on Australian adolescents' smoking? Findings over a 15-year period," Addiction, vol. 106, no. 8, pp. 14931502, 2011.

[17] C. Carpenter and P. J. Cook, "Cigarette taxes and youth smoking: new evidence from national, state, and local Youth Risk Behavior Surveys," Journal of Health Economics, vol. 27, no. 2, pp. 287-299, 2008.

[18] A. Ding, "Youth are more sensitive to price changes in cigarettes than adults," Yale Journal of Biology and Medicine, vol. 76, no. 1-6, pp. 115-124, 2003.

[19] B. J. Waller, J. E. Cohen, R. Ferrence, S. Bull, and E. M. Adlaf, "The early 1990s cigarette price decrease and trends in youth smoking in Ontario," Canadian Journal of Public Health, vol. 94, no. 1, pp. 31-35, 2003.

[20] J. Gruber, "Youth smoking in the US: prices and policies," NBER Working Paper No. 7506, 2000.

[21] F. J. Chaloupka and R. L. Pacula, "Limiting youth access to tobacco: the early impact of the synar amendment on youth smoking," Working Paper, Department of Economics, University of Illinois at Chicago, 1998.

[22] H. Ross, E. Blecher, L. Yan, and A. Hyland, "Do cigarette prices motivate smokers to quit? New evidence from the ITC survey," Addiction, vol. 106, no. 3, pp. 609-619, 2011.

[23] B. Saenz-de-Miera, J. F. Thrasher, F. J. Chaloupka, H. R. Waters, M. Hernandez-Avila, and G. T. Fong, "Selfreported price of cigarettes, consumption and compensatory behaviours in a cohort of Mexican smokers before and after a cigarette tax increase," Tobacco control, vol. 19, no. 6, pp. 481-487, 2010.

[24] R. Hanewinkel and B. Isensee, "Five in a row - Reactions of smokers to tobacco tax increases: population-based crosssectional studies in Germany 2001-2006," Tobacco Control, vol. 16, no. 1, pp. 34-37, 2007.

[25] G. A. Franz, "Price effects on the smoking behaviour of adult age groups," Public Health, vol. 122, no. 12, pp. 1343-1348, 2008.

[26] M. B. Reed, C. M. Anderson, J. W. Vaughn, and D. M. Burns, "The effect of cigarette price increases on smoking cessation in California," Prevention Science, vol. 9, no. 1, pp. 47-54, 2008.

[27] M. A. Wakefield, S. Durkin, M. J. Spittal et al., "Impact of tobacco control policies and mass media campaigns on monthly adult smoking prevalence," American Journal of Public Health, vol. 98, no. 8, pp. 1443-1450, 2008.

[28] S. Azagba and M. Sharaf, "Cigarette taxes and smoking participation: evidence from recent tax increases in Canada," International Journal of Environmental Research and Public Health, vol. 8, no. 5, pp. 1583-1600, 2011.

[29] P. M. Lance, J. S. Akin, W. H. Dow, and C. P. Loh, "Is cigarette smoking in poorer nations highly sensitive to price? Evidence 
from Russia and China," Journal of Health Economics, vol. 23, no. 1, pp. 173-189, 2004.

[30] M. Siahpush, M. A. Wakefield, M. J. Spittal, S. J. Durkin, and M. M. Scollo, "Taxation reduces social disparities in adult smoking prevalence," American Journal of Preventive Medicine, vol. 36, no. 4, pp. 285-291, 2009.

[31] P. DeCicca and L. McLeod, "Cigarette taxes and older adult smoking: evidence from recent large tax increases," Journal of Health Economics, vol. 27, no. 4, pp. 918-929, 2008.

[32] P. Franks, A. F. Jerant, J. P. Leigh et al., "Cigarette prices, smoking, and the poor: implications of recent trends," American Journal of Public Health, vol. 97, no. 10, pp. 18731877, 2007.

[33] F. A. Sloan and J. G. Trogdon, "The impact of the master settlement agreement on cigarette consumption," Journal of Policy Analysis and Management, vol. 23, no. 4, pp. 843-855, 2004.

[34] S. Gallus, E. Fernandez, J. Townsend, A. Schiaffino, and C. La Vecchia, "Price and consumption of tobacco in Italy over the last three decades," European Journal of Cancer Prevention, vol. 12, no. 4, pp. 333-337, 2003.

[35] M. Scollo, S. Younie, M. Wakefield, J. Freeman, and F. Icasiano, "Impact of tobacco tax reforms on tobacco prices and tobacco use in Australia," Tobacco Control, vol. 12, supplement 2, pp. 59-66, 2003.

[36] C. van Walbeek, "Recent trends in smoking prevalence in South Africa-some evidence from AMPS data," South African Medical Journal, vol. 92, no. 6, pp. 468-472, 2002.

[37] M. C. Farrelly, J. W. Bray, T. Pechacek, and T. Woollery, "Response by adults to increases in cigarette prices by sociodemographic characteristics," Southern Economic Journal, vol. 68, no. 1, pp. 156-165, 2001.

[38] I. Bogdanovica, R. Murray, A. McNeill, and J. Britton, "Cigarette price, affordability and smoking prevalence in the European Union," Addiction, vol. 107, pp. 188-196, 2012.

[39] J. A. Jimenez-Ruiz, B. Saenz de Miera, L. M. ReynalesShigematsu, H. R. Waters, and M. Hernandez-Avila, "The impact of taxation on tobacco consumption in Mexico," Tobacco Control, vol. 17, pp. 105-110, 2008.

[40] T. W. Hu, Z. Mao, J. Shi, and W. Chen, "The role of taxation in tobacco control and its potential economic impact in China," Tobacco Control, vol. 19, no. 1, pp. 58-64, 2010.

[41] S. S. Hawkins, T. J. Cole, and C. Law, "Examining smoking behaviours among parents from the UK millennium cohort study after the smoke-free legislation in Scotland," Tobacco Control, vol. 20, no. 2, pp. 112-118, 2011.

[42] E. G. Klein, "The unintended consequences of clean indoor air policies in Minnesota," Dissertation Abstracts International $B$, vol. 68 , no. 9, 2008.

[43] L. Biener, W. L. Hamilton, M. Siegel, and E. M. Sullivan, "Individual, Social-normative, and policy predictors of smoking cessation: a multilevel longitudinal analysis," American Journal of Public Health, vol. 100, no. 3, pp. 547554, 2010.

[44] A. Hyland, L. M. Hassan, C. Higbee et al., "The impact of smokefree legislation in Scotland: results from the Scottish ITC Scotland/UK longitudinal surveys," European Journal of Public Health, vol. 19, no. 2, pp. 198-205, 2009.

[45] M. de L. Bauza-Amengual, M. Blasco-Gonzalez, E. SanchezVazquez, I. Pereiro-Berenguer, N. Ruiz-Varea, and J. PericasBeltran, "Impact of the Tobacco Law on the workplace: a follow up study of a cohort of workers in Spain 2005-2007," Aten Primaria, vol. 42, pp. 309-313, 2010.
[46] J. M. Murphy, S. L. De Moreno, K. M. Cummings, A. Hyland, and M. C. Mahoney, "Changes in cigarette smoking, purchase patterns, and cessation-related behaviors among low-income smokers in New York state from 2002 to 2005," Journal of Public Health Management and Practice, vol. 16, no. 4, pp. 277-284, 2010.

[47] S. Orbell, P. Lidierth, C. J. Henderson et al., "Social-cognitive beliefs, alcohol, and tobacco use: a prospective community study of change following a ban on smoking in public places," Health Psychology, vol. 28, no. 6, pp. 753-761, 2009.

[48] J. M. Martinez-Sanchez, E. Fernandez, M. Fu et al., "Impact of the Spanish smoking law in smoker hospitality workers," Nicotine \& Tobacco Research, vol. 11, pp. 1099-1106, 2009.

[49] F. J. I. Fowkes, M. C. W. Stewart, F. G. R. Fowkes, A. Amos, and J. F. Price, "Scottish smoke-free legislation and trends in smoking cessation," Addiction, vol. 103, no. 11, pp. 18881895, 2008.

[50] C. De Chaisemartin, P. Y. Geoffard, and A. L. Le Faou, "Workplace smoking ban effects on unhappy smokers," Health Economics, vol. 20, pp. 1043-1055, 2011.

[51] E. J. Hahn, M. K. Rayens, S. L. Ridner, K. M. Butler, M. Zhang, and R. R. Staten, "Smoke-free laws and smoking and drinking among college students," Journal of Community Health, vol. 35, no. 5, pp. 503-511, 2010.

[52] E. J. Hahn, M. K. Rayens, K. M. Butler, M. Zhang, E. Durbin, and D. Steinke, "Smoke-free laws and adult smoking prevalence," Preventive Medicine, vol. 47, no. 2, pp. 206-209, 2008.

[53] M. Lemstra, C. Neudorf, and J. Opondo, "Implications of a public smoking ban," Canadian Journal of Public Health, vol. 99, no. 1, pp. 62-65, 2008.

[54] E. G. Klein, J. L. Forster, D. J. Erickson, L. A. Lytle, and B. Schillo, "The relationship between local clean indoor air policies and smoking behaviours in minnesota youth," Tobacco Control, vol. 18, no. 2, pp. 132-137, 2009.

[55] S. Gallus, P. Zuccaro, P. Colombo et al., "Effects of new smoking regulations in Italy," Annals of Oncology, vol. 17, no. 2, pp. 346-347, 2006.

[56] F. Guerrero, F. J. Santonja, and R. J. Villanueva, "Analysing the Spanish smoke-free legislation of 2006: a new method to quantify its impact using a dynamic model," International Journal of Drug Policy, vol. 22, no. 4, pp. 247-251, 2011.

[57] D. F. Mackay, S. Haw, and J. P. Pell, "Impact of Scottish smoke-free legislation on smoking quit attempts and prevalence," PLoS One, vol. 6, Article ID e26188, 2011.

[58] B. J. Mullally, B. A. Greiner, S. Allwright, G. Paul, and I. J. Perry, "The effect of the Irish smoke-free workplace legislation on smoking among bar workers," European Journal of Public Health, vol. 19, no. 2, pp. 206-211, 2009.

[59] I. Galan, N. Mata, C. Estrada et al., "Impact of the "Tobacco control law" on exposure to environmental tobacco smoke in Spain," BMC Public Health, vol. 7, article 224, 2007.

[60] S. J. Haw and L. Gruer, "Changes in exposure of adult non-smokers to secondhand smoke after implementation of smoke-free legislation in Scotland: National Cross sectional survey," British Medical Journal, vol. 335, no. 7619, pp. 549552, 2007.

[61] J. T. Lee, S. A. Glantz, and C. Millett, "Effect of smoke-free legislation on adult smoking behaviour in England in the 18 months following implementation," PLoS One, vol. 6, no. 6, Article ID e20933, 2011.

[62] P. J. Elton and P. Campbell, "Smoking prevalence in a north-west town following the introduction of Smoke-free 
England," Journal of Public Health, vol. 30, no. 4, pp. 415-420, 2008.

[63] S. Anger, M. Kvasnicka, and T. Siedler, "One last puff? Public smoking bans and smoking behavior," Journal of Health Economics, vol. 30, no. 3, pp. 591-601, 2011.

[64] W. M. Verdonk-Kleinjan, M. J. Candel, R. A. Knibbe, M. C. Willemsen, and H. de Vries, "Effects of a workplace-smoking ban in combination with tax increases on smoking in the Dutch population," Nicotine \& Tobacco Research, vol. 13, pp. 412-418, 2011.

[65] M. P. Bitler, C. Carpenter, and M. Zavodny, "Smoking restrictions in bars and bartender smoking in the US, 19922007," Tobacco Control, vol. 20, no. 3, pp. 196-200, 2011.

[66] M. P. Bitler, C. S. Carpenter, and M. Zavodny, "Effects of venue-specific state clean indoor air laws on smoking-related outcomes," Health Economics, vol. 19, no. 12, pp. 1425-1440, 2010.

[67] J. C. F. Galduróz, A. M. Fonseca, A. R. Noto, and E. A. Carlini, "Decrease in tobacco use among Brazilian students: a possible consequence of the ban on cigarette advertising?" Addictive Behaviors, vol. 32, no. 6, pp. 1309-1313, 2007.

[68] R. Fielding, Y. Y. Chee, K. M. Choi et al., "Declines in tobacco brand recognition and ever-smoking rates among young children following restrictions on tobacco advertisements in Hong Kong," Journal of Public Health, vol. 26, no. 1, pp. 2430, 2004.

[69] R. Borland, "Tobacco health warnings and smoking-related cognitions and behaviours," Addiction, vol. 92, no. 11, pp. 1427-1435, 1997.

[70] R. Borland, H. H. Yong, N. Wilson et al., "How reactions to cigarette packet health warnings influence quitting: findings from the ITC Four-Country survey," Addiction, vol. 104, no. 4, pp. 669-675, 2009.

[71] N. Gospodinov and I. J. Irvine, "Global health warnings on tobacco packaging: evidence from the Canadian experiment," Topics in Economic Analysis and Policy, vol. 4, no. 1, pp. 829$851,2004$.

[72] J. W. Linkenbach and H. W. Perkins, "MOST of us are tobacco free: an eight-month social norms campaign reducing youth initiation of smoking in Montana," in The Social Norms Approach to Preventing School and College Age Substance Abuse: A Handbook for Educators, Counselors, and Clinicians, H. W. Perkins, Ed., pp. 224-234, Jossey-Bass, San Francisco, Calif, USA, 2003.

[73] B. S. Flynn, J. K. Worden, R. H. Secker-Walker, P. L. Pirie, G. J. Badger, and J. H. Carpenter, "Long-term responses of higher and lower risk youths to smoking prevention interventions," Preventive Medicine, vol. 26, no. 3, pp. 389-394, 1997.

[74] A. Hafstad, L. E. Aarø, A. Engeland, A. Andersen, F. Langmark, and B. Stray-Pedersen, "Provocative appeals in antismoking mass media campaigns targeting adolescents-the accumulated effect of multiple exposures," Health Education Research, vol. 12, no. 2, pp. 227-236, 1997.

[75] M. C. Farrelly, J. Nonnemaker, K. C. Davis, and A. Hussin, "The influence of the National Truth campaign on smoking initiation," American Journal of Preventive Medicine, vol. 36, no. 5, pp. 379-384, 2009.

[76] G. Ronda, P. Van Assema, M. Candel et al., "The Dutch Heart Health Community Intervention "Hartslag Limburg": effects on smoking behaviour," European Journal of Public Health, vol. 14, no. 2, pp. 191-193, 2004.

[77] H. J. Steenkamp, P. L. Jooste, P. C. J. Jordaan, A. S. P. Swanepoel, and J. E. Rossouw, "Changes in smoking during a community-based cardiovascular disease intervention programme. The Coronary Risk Factor Study," South African Medical Journal, vol. 79, no. 5, pp. 250-253, 1991.

[78] M. C. Farrelly, K. C. Davis, M. L. Haviland, P. Messeri, and C. G. Healton, "Evidence of a dose-response relationship between "truth" antismoking ads and youth smoking prevalence," American Journal of Public Health, vol. 95, no. 3, pp. 425-431, 2005.

[79] D. F. Sly, G. R. Heald, and S. Ray, "The Florida "truth" anti-tobacco media evaluation: design, first year results, and implications for planning future state media evaluations," Tobacco Control, vol. 10, no. 1, pp. 9-15, 2001.

[80] L. J. Solomon, J. Y. Bunn, B. S. Flynn, P. L. Pirie, J. K. Worden, and T. Ashikaga, "Mass media for smoking cessation in adolescents," Health Education and Behavior, vol. 36, no. 4, pp. 642-659, 2009.

[81] Y. M. Terry-McElrath, S. Emery, M. A. Wakefield, P. M. O’Malley, G. Szczypka, and L. D. Johnston, "Effects of tobacco-related media campaigns on smoking among 2030-year-old adults: longitudinal data from the USA," Tobacco Control. In press.

[82] E. K. Burns and A. H. Levinson, "Reaching spanish-speaking smokers: state-level evidence of untapped potential for quitLine utilization," American Journal of Public Health, vol. 100, no. 1, pp. S165-S170, 2010.

[83] B. S. Flynn, J. K. Worden, J. Y. Bunn et al., "Mass media interventions to reduce youth smoking prevalence," American Journal of Preventive Medicine, vol. 39, no. 1, pp. 53-62, 2010.

[84] N. Arunatilake, "An economic analysis of tobacco demand in Sri Lanka," Sri Lanka Economic Journal, vol. 3, no. 1, pp. 96120, 2002.

[85] F. J. Chaloupka, T. Hu, K. E. Warner, R. Jacobs, and A. Yurekli, "The taxation of tobacco products," in Tobacco Control in Developing Countries, P. Jha and F. Chaloupka, Eds., pp. 237272, Oxford University Press, New York, NY, USA, 2000.

[86] IARC Handbooks of Cancer Prevention, Tobacco Control, Vol. 13: Evaluating the effectiveness of smoke-free policies, International Agency for Research on Cancer, Lyon, France, 2009.

[87] Institute of Medicine, Secondhand Smoke Exposure and Cardiovascular Effects: Making Sense of the Evidence, The National Academies Press, Washington, DC, USA, 2009.

[88] K. Warner, Tobacco Control Policy, Jossey-Bass, San Francisco, Calif, USA, 2006.

[89] U.S. Department of Health and Human Services, Public Health Service Centers for Disease Control and Prevention, Preventing tobacco use among young people: a report of the Surgeon General, U.S. Government Printing Office, Washington, DC, USA, 1994.

[90] National Cancer Institute, Smoking and Tobacco Control Monograph 14, US Department of Health and Human Services, National Institutes of Health, Bethesda, Md, USA.

[91] J. R. DiFranza, R. J. Wellman, J. D. Sargent, M. Weitzman, B. J. Hipple, and J. P. Winickoff, "Tobacco promotion and the initiation of tobacco use: assessing the evidence for causality," Pediatrics, vol. 117, no. 6, pp. e1237-e1248, 2006.

[92] A. Brown and C. Moodie, "The influence of tobacco marketing on adolescent smoking intentions via normative beliefs," Health Education Research, vol. 24, no. 4, pp. 721733, 2009.

[93] R. J. Wellman, D. B. Sugarman, J. R. DiFranza, and J. P. Winickoff, "The extent to which tobacco marketing and tobacco use in films contribute to children's use of tobacco: a 
meta-analysis," Archives of Pediatrics and Adolescent Medicine, vol. 160, no. 12, pp. 1285-1296, 2006.

[94] H. Saffer and F. Chaloupka, "The effect of tobacco advertising bans on tobacco consumption," Journal of Health Economics, vol. 19, no. 6, pp. 1117-1137, 2000.

[95] D. Hammond, G. T. Fong, A. McNeill, R. Borland, and K. M. Cummings, "Effectiveness of cigarette warning labels in informing smokers about the risks of smoking: Findings from the International Tobacco Control (ITC) Four Country Survey," Tobacco Control, vol. 15, no. 3, pp. 19-25, 2006.

[96] D. Hammond, G. T. Fong, R. Borland, K. M. Cummings, A. McNeill, and P. Driezen, "Text and graphic warnings on cigarette packages: findings from the international tobacco control four country study," American Journal of Preventive Medicine, vol. 32, no. 3, pp. 202-209, 2007.

[97] Institute of Medicine, Ending the Tobacco Problem: A Blueprint for the Nation, The National Academies Press, Washington, DC, USA, 2007.

[98] J. F. Thrasher, D. Hammond, G. T. Fong, and E. ArilloSantillán, "Smokers' reactions to cigarette package warnings with graphic imagery and with only text: a comparison between Mexico and Canada," Salud Publica de Mexico, vol. 49, no. 2, pp. S233-S240, 2007.

[99] D. Hammond, P. W. McDonald, G. T. Fong, K. S. Brown, and R. Cameron, "The impact of cigarette warning labels and smoke-free bylaws on smoking cessation: evidence from former smokers," Canadian Journal of Public Health, vol. 95, no. 3, pp. 201-204, 2004.

[100] V. White, B. Webster, and M. Wakefield, "Do graphic health warning labels have an impact on adolescents' smokingrelated beliefs and behaviours?" Addiction, vol. 103, no. 9, pp. 1562-1571, 2008.

[101] D. Hammond, G. T. Fong, P. W. McDonald, R. Cameron, and K. S. Brown, "Impact of the graphic Canadian warning labels on adult smoking behaviour," Tobacco Control, vol. 12, no. 4, pp. 391-395, 2003.

[102] A. I. Fathelrahman, M. Omar, R. Awang et al., "Smokers' responses toward cigarette pack warning labels in predicting quit intention, stage of change, and self-efficacy," Nicotine and Tobacco Research, vol. 11, no. 3, pp. 248-253, 2009.

[103] National Cancer Institute, The Role of the Media in Promoting and Reducing Tobacco Use, Tobacco Control Monograph No. 19, U.S. Department of Health and Human Services, National Institutes of Health, National Cancer Institute, Bethesda, Md, USA, 2008.

[104] M. Wakefield, B. Flay, M. Nichter, and G. Giovino, "Role of the media in influencing trajectories of youth smoking," Addiction, vol. 98, no. 1, pp. 79-103, 2003.

[105] M. C. Farrelly, J. Niederdeppe, and J. Yarsevich, "Youth tobacco prevention mass media campaigns: past, present, and future directions," Tobacco Control, vol. 12, pp. 35-47, 2003.

[106] M. C. Farrelly, C. G. Healton, K. C. Davis, P. Messeri, J. C. Hersey, and M. L. Haviland, "Getting to the truth: evaluating national tobacco countermarketing campaigns," American Journal of Public Health, vol. 92, no. 6, pp. 901-907, 2002.

[107] D. P. Hopkins, P. A. Briss, C. J. Ricard et al., "Reviews of evidence regarding interventions to reduce tobacco use and exposure to environmental tobacco smoke (Structured abstract)," American Journal of Preventive Medicine, vol. 20, no. 2, pp. 16-66, 2001.

[108] M. Bala, L. Strzeszynski, and K. Cahill, "Mass media interventions for smoking cessation in adults.," Cochrane
Database of Systematic Reviews, no. 1, Article ID CD004704, 2008.

[109] National Cancer Institute, Evaluating ASSIST: A Blueprint for Understanding State-level Tobacco Control, Tobacco Control Monograph No. 17, U.S. Department of Health and Human Services, National Institutes of Health, National Cancer Institute, Bethesda, Md, USA, 2006.

[110] T. R. Frieden, F. Mostashari, B. D. Kerker, N. Miller, A. Hajat, and M. Frankel, "Adult tobacco use levels after intensive tobacco control measures: New York City, 20022003," American Journal of Public Health, vol. 95, no. 6, pp. 1016-1023, 2005.

[111] California Department of Public Health and California Tobacco Control Program, "California Tobacco Control Update 2009: 20 Years of Tobacco Control in California," Sacramento, Calif, USA, 2009.

[112] D. T. Levy, E. A. Mumford, and D. A. Gerlowski, "Examining trends in quantity smoked," Nicotine and Tobacco Research, vol. 9, no. 12, pp. 1287-1296, 2007.

[113] H. Y. Sung, T. W. Hu, M. Ong, T. E. Keeler, and M. L. Sheu, "A major state tobacco tax increase, the master settlement agreement, and cigarette consumption: the California experience," American Journal of Public Health, vol. 95, no. 6, pp. 10301035, 2005.

[114] M. Stehr, "Cigarette tax avoidance and evasion," Journal of Health Economics, vol. 24, no. 2, pp. 277-297, 2005.

[115] "Response to increases in cigarette prices by race/ethnicity, income, and age groups-United States, 1976-1993," Morbidity and Mortality Weekly Report, vol. 47, pp. 605-609, 1998.

[116] K. J. Meier and M. J. Licari, "The effect of cigarette taxes on cigarette consumption, 1955 through 1994," American Journal of Public Health, vol. 87, no. 7, pp. 1126-1130, 1997.

[117] T. W. Hu, H. Y. Sung, and T. E. Keeler, "Reducing cigarette consumption in California: tobacco taxes vs an anti-smoking media campaign," American Journal of Public Health, vol. 85, no. 9, pp. 1218-1222, 1995.

[118] T. E. Keeler, T. W. Hu, P. G. Barnett, and W. G. Manning, "Taxation, regulation, and addiction: a demand function for cigarettes based on time-series evidence," Journal of Health Economics, vol. 12, no. 1, pp. 1-18, 1993.

[119] R. L. Flewelling, E. Kenney, J. P. Elder, J. Pierce, M. Johnson, and D. G. Bal, "First-year impact of the 1989 California cigarette tax increase on cigarette consumption," American Journal of Public Health, vol. 82, no. 6, pp. 867-869, 1992.

[120] D. E. Peterson, S. L. Zeger, P. L. Remington, and H. A. Anderson, "The effect of state cigarette tax increases on cigarette sales, 1955 to 1988," American Journal of Public Health, vol. 82, no. 1, pp. 94-96, 1992.

[121] T. W. Hu, H. Y. Sung, and T. E. Keeler, "The state antismoking campaign and the industry response: the effects of advertising on cigarette consumption in California," The American economic review, vol. 85, no. 2, pp. 85-90, 1995.

[122] H.-Y. Sung, T.-W. Hu, and T. E. Keeler, "Cigarette taxation and demand: an empirical model," Contemporary Economic Policy, vol. 12, no. 3, pp. 91-100, 1994.

[123] T. E. Keeler, T. W. Hu, W. G. Manning, and H. Y. Sung, "State tobacco taxation, education and smoking: controlling for the effects of omitted variables," National Tax Journal, vol. 54, no. 1, pp. 83-102, 2001.

[124] T. E. Keeler, T. W. Hu, M. Ong, and H. Y. Sung, "The US national Tobacco Settlement: the effects of advertising and price changes on cigarette consumption," Applied Economics, vol. 36, no. 15, pp. 1623-1629, 2004. 
[125] B. H. Baltagi and D. Levin, "Cigarette taxation: raising revenues and reducing consumption," Structural Change and Economic Dynamics, vol. 3, no. 2, pp. 321-335, 1992.

[126] E. Blecher, "The impact of tobacco advertising bans on consumption in developing countries," Journal of Health Economics, vol. 27, no. 4, pp. 930-942, 2008.

[127] M. J. Stewart, "The effect on tobacco consumption of advertising bans in OECD countries," International Journal of Advertising, vol. 12, no. 2, pp. 155-181, 1993.

[128] E. Guindon, A. M. Perucic, and D. Boisclair, "Higher tobacco prices and taxes in South-east Asia: an effective tool to reduce tobacco use, save lives and generate revenue," World Bank. Health, Nutrition and Population Discussion Paper 11. Economics of Tobacco Control, 2003.

[129] M. C. Farrelly, C. T. Nimsch, A. Hyland, and M. Cummings, "The effects of higher cigarette prices on tar and nicotine consumption in a cohort of adult smokers," Health Economics, vol. 13, no. 1, pp. 49-58, 2004.

[130] J. Gruber, A. Sen, and M. Stabile, "Estimating price elasticities when there is smuggling: the sensitivity of smoking to price in Canada," Journal of Health Economics, vol. 22, no. 5, pp. 821-842, 2003.

[131] J. W. Galbraith and M. Kaiserman, "Taxation, smuggling and demand for cigarettes in Canada: evidence from time-series data," Journal of Health Economics, vol. 16, no. 3, pp. 287-301, 1997.

[132] W. K. Mummery and L. C. Hagen, "Tobacco pricing, taxation, consumption and revenue: Alberta 1985-1995," Canadian Journal of Public Health, vol. 87, no. 5, pp. 314-316, 1996.

[133] F. S. Reinhardt and D. E. A. Giles, "Are cigarette bans really good economic policy?” Applied Economics, vol. 33, no. 11, pp. 1365-1368, 2001.

[134] P. Bardsley and N. Olekalns, "Cigarette and tobacco consumption: have anti-smoking policies made a difference?" Economic Record, vol. 75, no. 230, pp. 225-240, 1999.

[135] T. Szilágyi, "Higher cigarette Taxes-healthier people, wealthier state: the Hungarian experience," Central European Journal of Public Health, vol. 15, no. 3, pp. 122-126, 2007.

[136] R. Hanewinkel, C. Radden, and T. Rosenkranz, "Price increase causes fewer sales of factory-made cigarettes and higher sales of cheaper loose tobacco in Germany," Health Economics, vol. 17, no. 6, pp. 683-693, 2008.

[137] J. M. Lee, D. S. Liao, C. Y. Ye, and W. Z. Liao, "Effect of cigarette tax increase on cigarette consumption in Taiwan," Tobacco Control, vol. 14, no. 1, pp. 71-75, 2005.

[138] E. Fernandez, S. Gallus, A. Schiaffino et al., "Price and consumption of tobacco in Spain over the period 19652000," European Journal of Cancer Prevention, vol. 13, pp. 207-211, 2004.

[139] P. Borren and M. Sutton, "Are increases in cigarette taxation regressive?" Health economics, vol. 1, no. 4, pp. 245-253, 1992.

[140] S. Chapman and J. Richardson, "Tobacco excise and declining tobacco consumption: the case of Papua New Guinea," American Journal of Public Health, vol. 80, no. 5, pp. 537-540, 1990.

[141] Z. Z. Mao, J. L. Xiang, and Z. P. Kon, "Demand for cigarette and pricing policy," Chinese Health Economics, vol. 16, no. 6, pp. 50-52, 1997.

[142] T. Djutaharta, H. Viriya-Surya, N. Haidy, A. Pasay, H. Moertiningsih-Adioetomo, and S. Moertiningsih-Adioetomo, "Aggregate analysis of the impact of cigarette tax rate increases on tobacco consumption and governement revenue. The case of Indonesia," HNP Discussion Paper. Economics of Tobacco Control. Indonesia: World Bank, Paper No. 25, 2005.

[143] S. Michie, M. M. van Stralen, and R. West, "The behaviour change wheel: a new method for characterising and designing behaviour change interventions," Implementation Science, vol. 6 , no. 1, article no. 42, 2011.

[144] N. Gospodinov and I. Irvine, "Tobacco taxes and regressivity," Journal of Health Economics, vol. 28, no. 2, pp. 375-384, 2009.

[145] K. E. Bauman, J. LaPrelle, J. D. Brown, G. G. Koch, and C. A. Padgett, "The influence of three mass media campaigns on variables related to adolescent cigarette smoking: results of a field experiment," American Journal of Public Health, vol. 81, no. 5, pp. 597-604, 1991.

[146] S. J. Durkin, L. Biener, and M. A. Wakefield, "Effects of different types of antismoking ads on reducing disparities in smoking cessation among socioeconomic subgroups," American Journal of Public Health, vol. 99, no. 12, pp. 22172223, 2009.

[147] A. Hyland, M. Wakefield, C. Higbee, G. Szczypka, and K. M. Cummings, "Anti-tobacco television advertising and indicators of smoking cessation in adults: a cohort study," Health Education Research, vol. 21, no. 3, pp. 348-354, 2006.

[148] D. McVey and J. Stapleton, "Can anti-smoking television advertising affect smoking behaviour? Controlled trial of the health education authority for England's anti-smoking TV campaign," Tobacco Control, vol. 9, no. 3, pp. 273-282, 2000.

[149] B. S. Flynn, J. K. Worden, R. H. Secker-Walker, G. J. Badger, and B. M. Geller, "Cigarette smoking prevention effects of mass media and school interventions targeted to gender and age groups," Journal of Health Education, vol. 26, no. 2, pp. S45-S51, 1995.

[150] J. K. Worden, B. S. Flynn, L. J. Solomon, R. H. Secker-Walker, G. J. Badger, and J. H. Carpenter, "Using mass media to prevent cigarette smoking among adolescent girls," Health Education and Behavior, vol. 23, no. 4, pp. 453-468, 1996.

[151] B. S. Flynn, J. K. Worden, R. H. Secker-Walker, G. J. Badger, B. M. Geller, and M. C. Costanza, "Prevention of cigarette smoking through mass media intervention and school programs," American Journal of Public Health, vol. 82, no. 6, pp. 827-834, 1992.

[152] B. S. Flynn, J. K. Worden, R. H. Secker-Walker et al., "Mass media and school interventions for cigarette smoking prevention: effects 2 years after completion," American Journal of Public Health, vol. 84, no. 7, pp. 1148-1150, 1994.

[153] J. K. Worden and B. S. Flynn, "Using mass media to prevent cigarette smoking," in Public Health Communication: Evidence for Behavior Change, R. C. Hornik, Ed., pp. 23-33, Lawrence Erlbaum Associates, Mahwah, NJ, USA, 2002.

[154] A. F. Meshack, S. Hu, U. E. Pallonen, A. L. McAlister, N. Gottlieb, and P. Huang, "Texas tobacco prevention pilot initiative: processes and effects," Health Education Research, vol. 19, no. 6, pp. 657-668, 2004. 


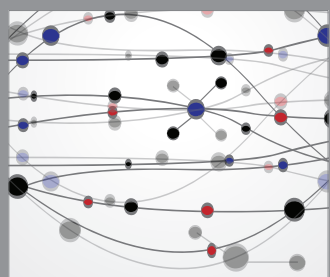

The Scientific World Journal
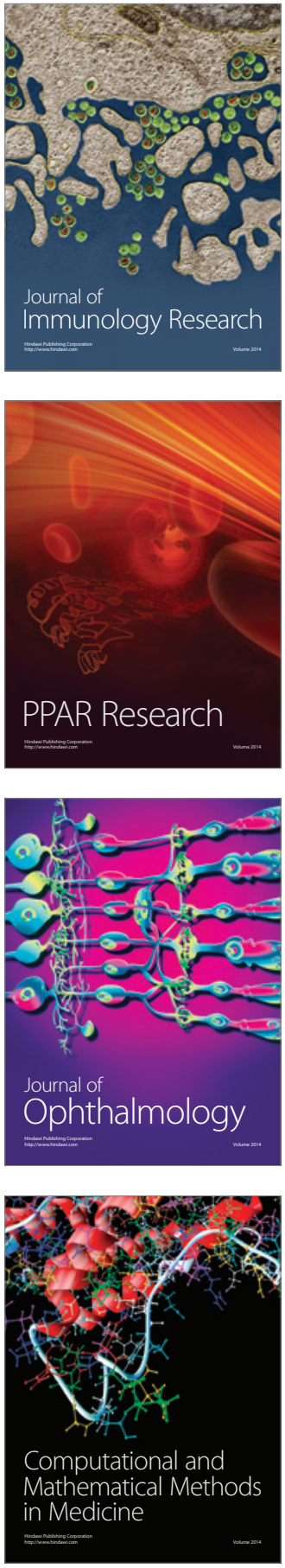

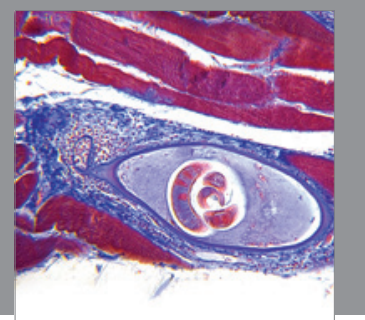

Gastroenterology

Research and Practice
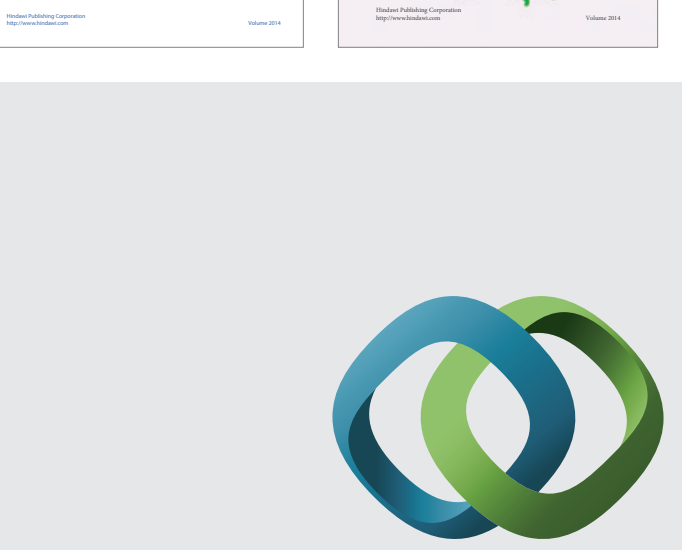

\section{Hindawi}

Submit your manuscripts at

http://www.hindawi.com
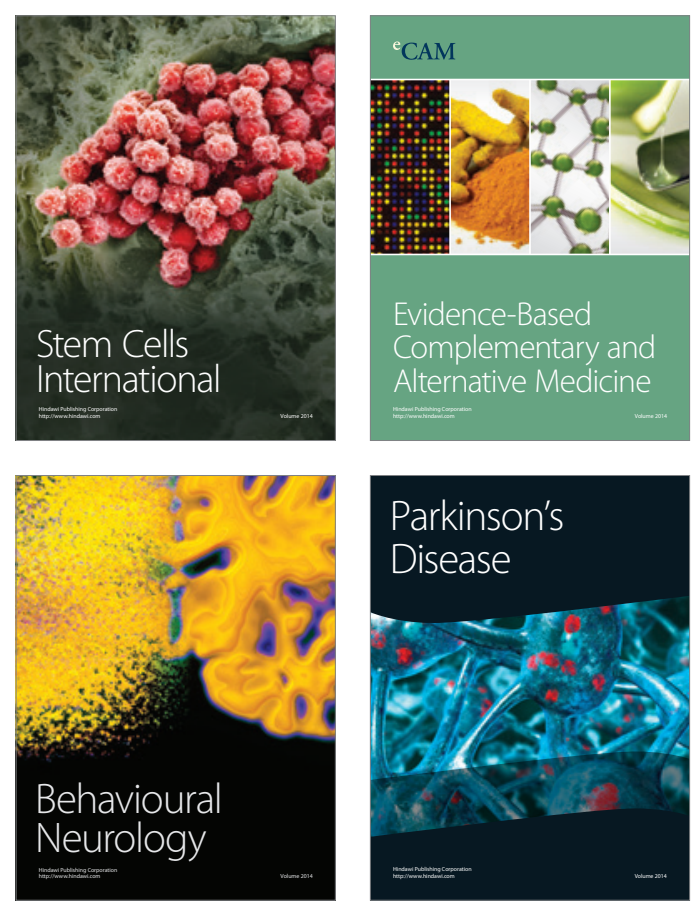

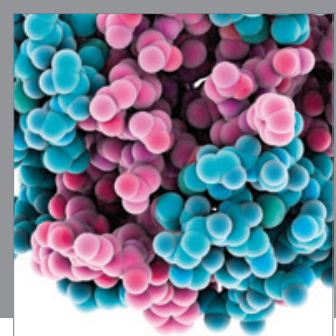

Journal of
Diabetes Research

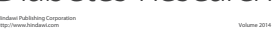

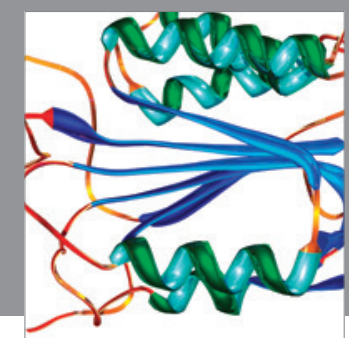

Disease Markers
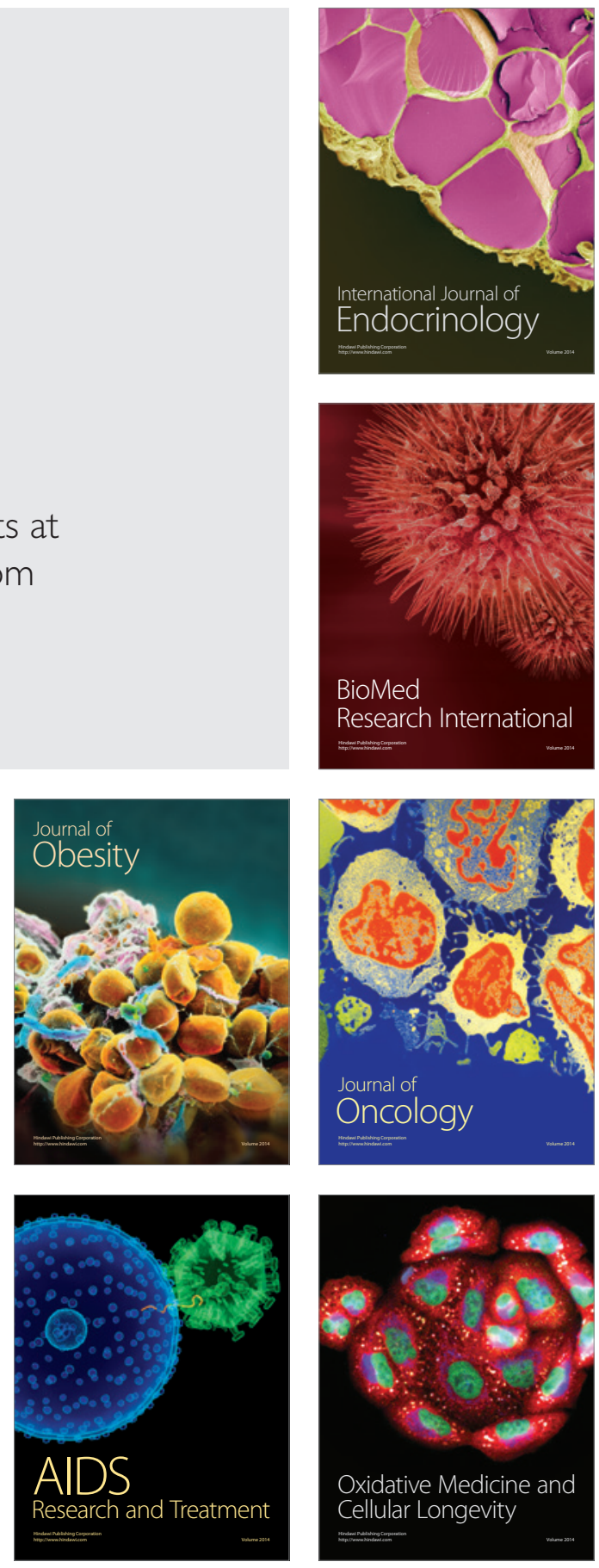